\title{
A Natural Light/Dark Cycle Regulation of Carbon-Nitrogen Metabolism and Gene Expression in Rice Shoots
}

\author{
Haixing Li, Zhijun Liang, Guangda Ding, Lei Shi, Fangsen Xu and Hongmei Cai * \\ Plant Nutrigenic and Molecular Biology, College of Resources and Environment, Huazhong Agricultural University, Wuhan, \\ China
}

Light and temperature are two particularly important environmental cues for plant survival. Carbon and nitrogen are two essential macronutrients required for plant growth and development, and cellular carbon and nitrogen metabolism must be tightly coordinated. In order to understand how the natural light/dark cycle regulates carbon and nitrogen metabolism in rice plants, we analyzed the photosynthesis, key carbon-nitrogen metabolites, and enzyme activities, and differentially expressed genes and miRNAs involved in the carbon and nitrogen metabolic pathway in rice shoots at the following times: 2:00, 6:00, 10:00, 14:00, 18:00, and 22:00. Our results indicated that more

Edited by:

Raul Antonio Sperotto, Centro Universitário UNIVATES, Brazil

Reviewed by:

Prateek Tripathi,

Scripps Research Institute, USA

Xusheng Wang,

St. Jude Children's Research Hospital,

USA

Autar Krishen Mattoo, United States Department of

Agriculture, USA

*Correspondence:

Hongmei Cai

caihongmei@mail.hzau.edu.cn

Specialty section:

This article was submitted to Plant Nutrition,

a section of the journal Frontiers in Plant Science

Received: 21 May 2016 Accepted: 17 August 2016 Published: 30 August 2016

Citation:

Li H, Liang Z, Ding G, Shi L, Xu F and Cai H (2016) A Natural Light/Dark Cycle Regulation of Carbon-Nitrogen

Metabolism and Gene Expression in Rice Shoots. Front. Plant Sci. 7:1318. doi: $10.3389 /$ fpls.2016.01318
$\mathrm{CO}_{2}$ was fixed into carbohydrates by a high net photosynthetic rate, respiratory rate, and stomatal conductance in the daytime. Although high levels of the nitrate reductase activity, free ammonium and carbohydrates were exhibited in the daytime, the protein synthesis was not significantly facilitated by the light and temperature. In mRNA sequencing, the carbon and nitrogen metabolism-related differentially expressed genes were obtained, which could be divided into eight groups: photosynthesis, TCA cycle, sugar transport, sugar metabolism, nitrogen transport, nitrogen reduction, amino acid metabolism, and nitrogen regulation. Additionally, a total of 78,306 alternative splicing events have been identified, which primarily belong to alternative $5^{\prime}$ donor sites, alternative $3^{\prime}$ acceptor sites, intron retention, and exon skipping. In sRNA sequencing, four carbon and nitrogen metabolism-related miRNAs (osa-miR1440b, osa-miR2876-5p, osa-miR1877 and osa-miR5799) were determined to be regulated by natural light/dark cycle. The expression level analysis showed that the four carbon and nitrogen metabolism-related miRNAs negatively regulated their target genes. These results may provide a good strategy to study how natural light/dark cycle regulates carbon and nitrogen metabolism to ensure plant growth and development.

Keywords: carbon, nitrogen, metabolism, gene, miRNA

\section{INTRODUCTION}

Nitrogen is one of the essential macronutrients required for plant growth and development. Nitrogen is not only a constituent of key cell molecules, such as nucleic acids, ATP, amino acids, chlorophyll, and several plant hormones, but is also the pivotal regulator of numerous biological processes, including amino acid metabolism, protein synthesis, and carbon metabolism 
(Frink et al., 1999; Crawford and Forde, 2002). Therefore, nitrogen is often a major limiting factor for plant productivity and crop yield (Lam et al., 1996; Tabuchi et al., 2007). Carbon plays a crucial role in routine plant growth and development. Various carbon compounds, including organic acids, sucrose, glucose, and other carbohydrates, provide both the energy and the carbon skeletons for ammonium $\left(\mathrm{NH}_{4}^{+}\right)$assimilation. Nitrogen compounds are synthesized by incorporating $\mathrm{NH}_{4}^{+}$ into the carbon skeletons to produce various amino acids and subsequently proteins. Amino acids, proteins, and particularly enzymes, are essential for almost all cellular activities, including the nitrogen and carbon metabolic reactions (Zheng, 2009). Therefore, both nitrogen and carbon nutrients are essential for plant cellular functions. Recently, it has been recognized that cellular carbon and nitrogen metabolism must be tightly coordinated (Zheng, 2009; Nunes-Nesi et al., 2010; Bao et al., 2014, 2015b). Maintaining a coordination of carbon-nitrogen metabolism and an appropriate balance of carbohydrates to nitrogen metabolites, also referred to as the "carbon/nitrogen balance," is important for plant growth, development, and yield production (Coruzzi and Zhou, 2001; Krapp et al., 2002; Martin et al., 2002; Krapp and Truong, 2005; Zheng, 2009; Nunes-Nesi et al., 2010). Our previous study also indicated the importance of carbon-nitrogen metabolic balance in rice growth and development (Bao et al., 2014, 2015a,b).

The Earth's rotation around its axis generates daily and seasonal light and temperature changes. In order to coordinate these periodic environmental changes, many organisms have acquired the capacity to regulate their critical biological processes temporally by an endogenous rhythm, known as the circadian clock (Dodd et al., 2005; Harmer, 2009). Because plants are sessile, light, and temperature are two particularly important environmental cues for plant survival, as they must be able to sense environmental changes and adapt to them properly from day to day and season to season. The plant circadian clock generates a light/dark cycle close to $24 \mathrm{~h}$. During the daytime, photosynthesis provides the plant energy and carbohydrates for growth and development, while at nighttime, plant metabolism, and growth depend on the carbohydrates that accumulated from photosynthesis during the day time to avoid starvation in the dark. A previous study reported that approximately $50 \%$ of the carbon assimilated during the daytime accumulates as starch in the leaves of Arabidopsis thaliana (Zeeman and Rees, 1999). At night, starch is degraded almost linearly to provide sugars for plant growth, with 5-10\% remaining at dawn (Gibon et al., 2004; Smith and Stitt, 2007; Graf and Smith, 2011).

Therefore, to ensure the optimal physiology, growth, and behavior in light/dark cycles, a wide variety of plant metabolic events are regulated by the circadian clock and show the daily oscillation patterns, including photosynthesis, nutrient assimilation, redox homeostasis, starch metabolism, and secondary metabolism (Dodd et al., 2005; Lu et al., 2005; Gutiérrez et al., 2008; Graf et al., 2010; Kerwin et al., 2011; Lai et al., 2012). Metabolomics analysis revealed that $~ 30 \%$ of the measured primary metabolites showed the circadian clock controlled in Arabidopsis (Espinoza et al., 2010). Additionally, various transcriptional and post-transcriptional events are regulated by the circadian clock, which changes the plants' responses and sensitivities to various external stimuli and makes them obtain specific information throughout the day and night. Transcriptome analysis revealed that about one third of all genes are circadian clock regulated in Arabidopsis, such as those involved in photosynthesis and starch metabolism, nitrogen and sulfur metabolism, chlorophyll and carotene biosynthesis, flavonoid and anthocyanin biosynthesis, sugar membrane transportation, and redox balance (Covington et al., 2008). Sato et al. (2013) also released the diurnal and circadian gene expression profile of rice leaf throughout entire growth in the field during sunrise, mid-day (12:00), sunset, and midnight (24:00) in RiceXPro. Post-transcriptional control, mediated largely through alternative splicing and miRNAs, has also been shown to have a rapid response to the circadian clock and environmental changes (Bartok et al., 2013).The first step of pre-mRNA splicing is the recognition of a specific target sequence in the intron-exon junction or inside the intron. If the splicing acceptor site does not perfectly fit the consensus sequence of the region, an alternative version of mRNA can be generated (Cáceres and Kornblihtt, 2002). This process is called alternative splicing and can lead to the generation of many mRNA isoforms from a single genomic sequence. A recent study demonstrated the importance of alternative splicing in Arabidopsis mediating circadian responses to temperature changes using a genome-wide approach (James et al., 2012). MiRNA is one of the posttranscriptional regulators of gene expression; it completely or partially binds with the target mRNA and mainly reduces the translation level or accelerates the turnover of target mRNA. MiRNAs have also been implicated in both the core circadian mechanism, and in the responses of the clock to the environment, especially in Drosophila and mammals (Bartok et al., 2013).

To date, studies have focused on the circadian regulation of photosynthesis, carbon metabolism, and allocation in plants under controlled conditions. Few studies have reported on the light/dark cycle regulation of plant nitrogen metabolism under natural field conditions. Moreover, there is still no comprehensive, whole-genome RNAseq, and small RNAseq analysis to study the transcriptional and post-transcriptional regulation of the natural light/dark cycle in rice plants. There is a close interaction between the carbon and nitrogen metabolism in plants. Thus, in this study, we first analyze the photosynthesis, key carbon-nitrogen metabolites, and enzyme activities in rice shoots at the times: 2:00, 6:00, 10:00, $14: 00,18: 00$, and 22:00, to understand how the natural light/dark cycle regulates carbon and nitrogen metabolism in rice plants. Later, we analyze the transcriptome and small RNAs in rice shoots at each of the time points mentioned above, using mRNAseq and sRNAseq techniques, to reveal the differentially expressed genes and miRNAs involving in the carbon and nitrogen metabolic pathway. The results demonstrated that in rice shoots, not only were metabolites and enzyme activities regulated by the natural light/dark cycle but also genes, miRNAs and alternative splicing events. 


\section{MATERIALS AND METHODS}

\section{Plant Growth and Sample Harvesting}

The seeds of Zhonghua 11 (Oryza sativa ssp. Japonica) were germinated and sowed in sand at the potting farm at Huazhong Agricultural University, Wuhan, China. At the five-leaf stage, the seedlings were planted in the field. After 4 weeks, three biological replicated fresh samples of the rice shoots were harvested at 2:00, 6:00, 10:00, 14:00, 18:00, and 22:00. Each sample contained three plants. All samples were stored at $-70^{\circ} \mathrm{C}$ and used for further analysis. At the same time, we monitored the photosynthetic parameters and the temperature when we harvested the samples at each time point. In the mRNA and small RNA sequencing analysis, we used 2:00 as the control time point to analyze the differentially expressed genes and miRNAs, because there was a lowest net photosynthetic rate in leaves at that time. Sunrise was at 5:00 and sundown at 19:00. Therefore, the daytime was from 5:00 to 19:00. Supplementary Figure $\mathbf{S 1}$ shows the diagram of rice germination, planting, and harvesting in this study.

\section{Carbon-Nitrogen Metabolites Determination}

(i) Photosynthetic parameter determination. At each time point, 10 plants were randomly selected for the determination of the photosynthetic parameters. The net photosynthetic rate, stomatal conductance, intercellular $\mathrm{CO}_{2}$ concentration, and transpiration rate of the first and second leaves from the top of the rice plants were tested by a Li-6400XT portable photosynthesis system (USA, Li-COR).

(ii) Chlorophyll content determination. Chlorophyll a and b contents were estimated according to the procedure described by Porra et al. (1989). Approximately $0.2 \mathrm{~g}$ shoot samples were excised into pieces and homogenized in $80 \%$ (v/v) acetone and kept in a dark room at $4^{\circ} \mathrm{C}$ until the green samples turned white. After centrifuging, the absorbency of the extracted solution was measured at 662 and $645 \mathrm{~nm}$ by a spectrophotometer. The chlorophyll content was calculated according to the formula given by Zhang (1990).

(iii) Free ammonium determination. Samples were freshly ground and homogenized with the extraction buffer [50 mM Tris $\mathrm{HCl}$ ( $\mathrm{pH} 7.0), 10 \mathrm{mM}$ imidazole, and $0.5 \%$ $(\mathrm{w} / \mathrm{v}) \beta$-mercaptoethanol] on ice. The homogenates were centrifuged at $12,000 \mathrm{~g}$ for $20 \mathrm{~min}$ at $4^{\circ} \mathrm{C}$. Free ammonium in the supernatant was determined by the Berthelot color reaction method (Hausler et al., 1994). The absorbance of the reacted solution was measured at $480 \mathrm{~nm}$ by a spectrophotometer, and the free ammonium content was calculated from the standard curve of $\mathrm{NH}_{4} \mathrm{NO}_{3}$.

(iv) Free amino acid determination. All steps followed the manufacturer's instructions (Hitachi Instruments Engineering, Japan). Samples were excised into pieces and immersed immediately in $80 \%(\mathrm{w} / \mathrm{v})$ ethanol at $80^{\circ} \mathrm{C}$ three times. Free amino acids were extracted and underwent diethylether extraction, freeze drying, and dissolution in $0.2 \mathrm{mM} \mathrm{HCl}$. Finally, the samples were analyzed by a Hitachi amino acid analyzer (L-8800) using leucine as a standard. (v) Soluble protein and carbohydrate determination. For soluble protein analysis, samples were freshly ground and homogenized with the extraction buffer [10 $\mathrm{mM}$ Trizma ( $\mathrm{pH}$ 7.5), $10 \mathrm{mM} \mathrm{MgSO}_{4}, 5 \mathrm{mM}$ sodium glutamate, 1 $\mathrm{mM}$ dithiothreitol, 10\% (v/v) glycerol, and $0.05 \%(\mathrm{v} / \mathrm{v})$ Triton X-100] on ice. The homogenates were centrifuged at $12,000 \mathrm{~g}$ for $20 \mathrm{~min}$ at $4^{\circ} \mathrm{C}$ (Melo et al., 2003). The soluble protein concentration in the supernatant was measured according to the Bradford method (Bradford, 1976) using Coomassie Plus Protein Assay Reagent (Pierce, Rockford, IL, USA). Bovine serum albumin was used as the standard protein. The soluble carbohydrates were extracted from pre-dried samples with boiling water and colorimetrically measured according to the Anthrone procedure (Morris, 1948; Maness, 2010).

\section{Carbon-Nitrogen Metabolic Enzyme Activity Measurement}

(i) Nitrate reductase activity measurement. Nitrate reductase activity in each sample was estimated based on the method described by Nakagawa et al. (1985). Approximately $0.5 \mathrm{~g}$ shoot samples were freshly ground and homogenized with the extraction buffer [0.05 g PVP; $0.5 \%(\mathrm{w} / \mathrm{v})$ PEG; $0.25 \%(\mathrm{w} / \mathrm{v}) \mathrm{Na}_{2} \mathrm{~S}_{2} \mathrm{O}_{3}$ and $15 \%(\mathrm{v} / \mathrm{v})$ glycerol] on ice. The homogenates were centrifuged at $12,000 \mathrm{~g}$ for $20 \mathrm{~min}$ at $4^{\circ} \mathrm{C}$. The determination of nitrate reductase activity in the supernatant was based on the formation of nitrite in a reaction medium containing $0.1 \mathrm{ml}$ enzyme extract, $0.2 \mathrm{ml} 13 \mathrm{mM} \mathrm{NADH}$, and $1.2 \mathrm{ml}$ buffer. The reaction was terminated by adding $1 \mathrm{ml} 1 \%$ sulfanilamide and $1 \mathrm{ml} \mathrm{0.02 \%}$ naphthyl ethylenediamine- $\mathrm{HCl}$.

(ii) Glutamine synthetase activity measurement. Samples were freshly ground with the extraction buffer $[70 \mathrm{mM}$ MOPS (pH 6.8), $10 \mathrm{mM} \mathrm{MgSO}_{4}, 5 \mathrm{mM}$ glutamate, $2 \mathrm{mM}$ dithiothreitol, $10 \%(\mathrm{v} / \mathrm{v})$ ethanediol and $0.1 \%(\mathrm{v} / \mathrm{v})$ Triton $\mathrm{X}-100]$ on ice. The homogenates were centrifuged at $12,000 \mathrm{~g}$ for $30 \mathrm{~min}$ at $4^{\circ} \mathrm{C}$ and the supernatant was used for glutamine synthetase activity analysis, according to the procedure described by Harrison et al. (2003). The supernatant was assayed with a pre-incubated buffer [100 mM glutamate, $70 \mathrm{mM}$ MOPS (pH 6.80), $50 \mathrm{mM}$ $\mathrm{MgSO}_{4}, 15 \mathrm{mM} \mathrm{NH} \mathrm{NH}_{2} \mathrm{OH}$, and $15 \mathrm{mM} \mathrm{ATP]}$ at $37^{\circ} \mathrm{C}$. The reaction was terminated after $30 \mathrm{~min}$ at $37^{\circ} \mathrm{C}$ by adding acidic $\mathrm{FeCl}_{3}$ solution $(670 \mathrm{mM} \mathrm{HCl}, 200 \mathrm{mM}$ trichloroacetic acid and $88 \mathrm{mM} \mathrm{FeCl}_{3}$ ). After allowing 10 min for the color to develop, the reaction mixture was centrifuged at $4000 \mathrm{~g}$ at room temperature for $10 \mathrm{~min}$. The absorbency of the supernatant was measured at 540 $\mathrm{nm}$ by a spectrophotometer, and the glutamine synthetase activity was calculated by quantifying the formation of $\gamma$-glutamylhydroxamate ( $\gamma$-GHA).

(iii) Glutamate synthase activity measurement. Approximately $0.2 \mathrm{~g}$ samples were freshly ground and homogenized with $1.5 \mathrm{ml}$ extraction buffer [50 mM Tris $\mathrm{HCl}(\mathrm{pH} 7.5), 10 \mathrm{mM}$ $\mathrm{MgCl}_{2}, 1 \mathrm{mM}$ EGTA, $1 \mathrm{mM}$ EDTA, $1 \mathrm{mM}$ benzamidine, $1 \mathrm{mM}$ PMSF, $1 \mathrm{mM} \varepsilon$-aminocaproic acid and $10 \mu \mathrm{M}$ 
leupeptin] on ice. The homogenates were centrifuged at $12,000 \mathrm{~g}$ for $20 \mathrm{~min}$ at $4^{\circ} \mathrm{C}$, and the supernatant was used for NADH- and Fd-glutamate synthase activity analysis, according to the procedure described by Hecht et al. (1988) and Migge et al. (1997), respectively.

(iv) Glutamate dehydrogenase activity measurement. Approximately $0.5 \mathrm{~g}$ samples were freshly ground and homogenized with $1.5 \mathrm{ml}$ extraction buffer [50 mM Tris $\mathrm{HCl}$ (pH 8.0), $1 \mathrm{mM}$ DTT, $1 \mathrm{mM} \mathrm{MgCl} 2,1.0 \mathrm{mM} \mathrm{MnCl}_{2}$ ] on ice. The homogenates were centrifuged at $10,000 \mathrm{~g}$ for $45 \mathrm{~min}$ at $4^{\circ} \mathrm{C}$, and the supernatant was used for glutamate dehydrogenase activity measurement, according to the procedure described by Kates and Jones (1964). Then, $0.1 \mathrm{ml}$ supernatant was reacted with $3 \mathrm{ml}$ reaction mixture [100 $\mu \mathrm{M} \mathrm{NH} \mathrm{NH}_{4} \mathrm{Cl}, 33 \mu \mathrm{M}$ Tris $\mathrm{HCl}(\mathrm{pH} 9.0), 4.0 \mu \mathrm{M}$ $\alpha$-ketoglutarate ( $\mathrm{pH} 7.0$ ), $1.0 \mu \mathrm{M} \mathrm{CaCl}_{2}, 1.0 \mu \mathrm{M} \mathrm{MgCl}$, $0.3 \mu \mathrm{M} \mathrm{NADH}, 0.1 \mu \mathrm{M}$ DTT] at $37^{\circ} \mathrm{C}$ for $20 \mathrm{~min}$. The absorbency of the reaction medium was measured at $340 \mathrm{~nm}$ by a spectrophotometer, and the glutamate dehydrogenase activity was calculated by quantifying the decreasing of $\mathrm{NADH}$.

\section{cDNA Library Construction and Sequencing}

For mRNA and small RNA sequencing analysis, the RNA extraction, cDNA library construction, and sequencing of rice shoot samples were carried out as a custom service by Personalbio (http://www.personalbio.cn). Total RNA was extracted by Trizol reagent (Invitrogen, Germany), according to the manufacturer's instructions. The cDNA library was constructed by TruSeq RNA Sample Prep Kit (Illumina), quantified by Quantifluor-ST fluorometer (Promega) and Quant-iTPicoGreen dsDNA Assay Kit (Invitrogen), qualified by Agilent 2100 Bioanalyzer and Agilent High Sensitivity DNA Kit. Later, samples were sequenced by Illumina Hiseq 2000.

\section{Data Analysis}

The original data quality evaluation, mapping back to the reference transcriptome gene, and small RNA annotation and expression analysis, and other bioinformatics analysis were also performed as a custom service by Personalbio (http://www. personalbio.cn). For the data from the mRNA sequencing, the useful reads were obtained by removing the ligation sequence and low quality sequences from original reads, and mapping to the rice reference genome (Oryza_sativa.IRGSP-1.0.21; $\mathrm{ftp}$ //ftp.ensemblgenomes.org/pub/release-21/plants/genbank/ oryza_sativa) by Bowtie2/tophat2 (http://tophat.cbcb.umd. edu). Genes were annotated from Oryza_sativa.IRGSP-1.0.21.gtf (ftp://ftp.ensemblgenomes.org/pub/release-21/plants/gtf/oryza_ sativa), and categorized by their biological functions from eggNOG analysis (http://www.ncbi.nlm.nih.gov/COG, http:// eggnog.embl.de/version_3.0; Tatusov et al., 2003; Powell et al., 2011). For the data from the small RNA sequencing, the clean reads (15-30 nt) were obtained by removing the ligation sequence and low quality sequences from raw reads. The unique sequences were mapped to the rice reference genome by Bowtie. Small RNAs were annotated by blasting with the database of Rfam (11.0), and miRNAs were blasted with the mature
miRNA sequences in rice. The number of mapped genes was analyzed by HTseq (http://www-huber.embl.de/users/anders/ HTSeq), and the differentially expressed genes were analyzed by DEseq (http://www-huber.embl.de/users/anders/DESeq) with parameters $p<0.05$, fold change $>2$ and FDR $<0.001$. The metabolic pathways of differentially expressed genes were analyzed by KEGG orthology (http://www.genome.jp/kegg/tool/ map_pathway2.html; Kanehisa et al., 2004). The differentially expressed genes and miRNAs were clustered by Cluster 3.0 /TreeView (http://bonsai.hgc.jp/ mdehoon/software/cluster/ software.htm, http://jtreeview.sourceforge.net). The target genes of miRNAs were predicted by psRNATarget (http://plantgrn. noble.org/psRNATarget/?function=3).

\section{QRT-PCR Analysis}

For qRT-PCR analysis, the total RNA was extracted with TriZol reagent (Invitrogen, Germany) and the first-strand cDNAs were synthesized from DNaseI-treated total RNA using Superscript II reverse transcriptase (Invitrogen, Germany) according to the manufacturer's instructions. QRT-PCR was performed in an optical 96-well-plate with an ABI PRISM 7500 real-time PCR system (Applied Biosystems, Foster City, CA, USA). Each reaction contained $12.5 \mu \mathrm{l}$ of $2 \times$ SYBR Green Master Mix reagent (Applied Biosystems), $3.0 \mu \mathrm{l}$ of cDNA, and $200 \mu \mathrm{M}$ each of the gene-specific primers in a final volume of $25 \mu \mathrm{l}$. The thermal cycle used was as follows: $95^{\circ} \mathrm{C}$ for $3 \mathrm{~min}$ followed by 45 cycles of $95^{\circ} \mathrm{C}$ for $30 \mathrm{~s}, 60^{\circ} \mathrm{C}$ for $30 \mathrm{~s}$, and $72^{\circ} \mathrm{C}$ for $40 \mathrm{~s}$. All gene-specific primers for q-RT PCR were designed on the basis of the cDNA sequences and listed in Supplementary Table S1. The specific primer for the rice actin gene (AK070531) was used as an internal control. The primers were designed using Primer Express Software (Foster City, CA, USA) and checked using the BLAST program with the rice genomic sequence available in the database of the Institute for Genomic Research (TIGR, http:// rice.plantbiology.msu.edu/) to ensure that the primers would amplify a unique and desired cDNA segment. The specificity of the reactions was checked by melting curve analysis, and three replicates of each cDNA sample were used for qRT-PCR analysis.

\section{RESULTS}

\section{Natural Light/Dark Cycle Regulation of Photosynthetic Parameters}

In order to study how natural light/dark cycle affected rice photosynthesis, we tested the photosynthetic parameters, including net photosynthetic rate, transpiration rate, stomatal conductance, and intercellular $\mathrm{CO}_{2}$ concentration, in the first and second leaves from the top of the rice plant at the times: 2:00, $6: 00,10: 00,14: 00,18: 00$, and 22:00, respectively (Figure 1). We also monitored the temperature when we harvested the samples at each time point. The temperature was $25.0^{\circ} \mathrm{C}$ at $2: 00,24.0^{\circ} \mathrm{C}$ at $6: 00,27.0^{\circ} \mathrm{C}$ at $10: 00,31.5^{\circ} \mathrm{C}$ at $14: 00,29.0^{\circ} \mathrm{C}$ at $18: 00$ and $26.0^{\circ} \mathrm{C}$ at 22:00, and there was an obvious peak of high temperature, $\left(31.5^{\circ} \mathrm{C}\right)$ at $14: 00$ in the daytime (Figure 2A). Generally, no significant differences were observed in the net photosynthetic rate, transpiration rate, and stomatal conductance, between the first and second leaves from the top of the rice plant, while the 

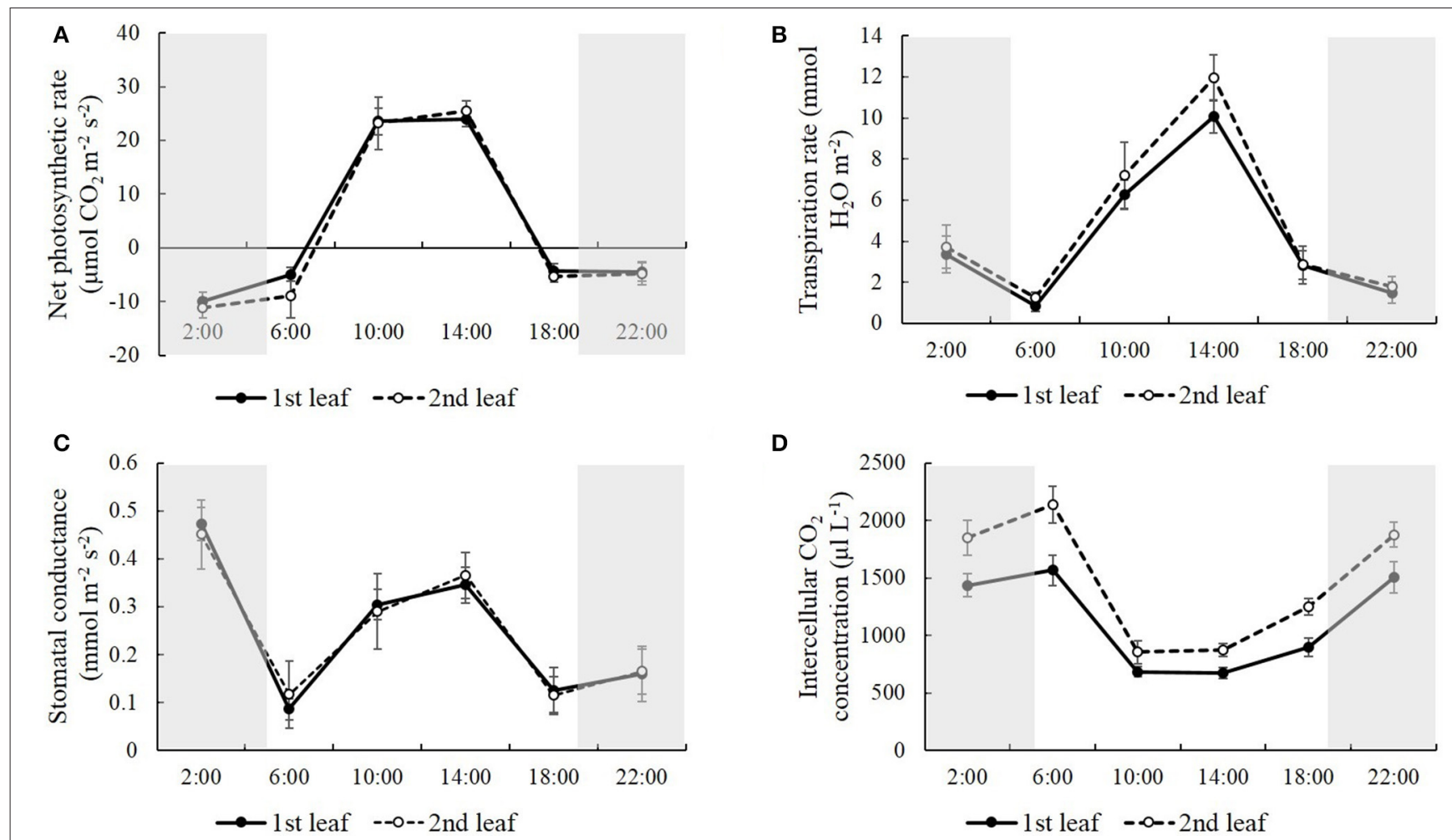

FIGURE 1 | The net photosynthetic rate (A), transpiration rate (B), stomatal conductance (C), and intercellular $\mathrm{CO}_{2}$ concentration (D) in the first and second leaves from the top of the rice plant at the time of 2:00, 6:00, 10:00, 14:00, 18:00, and 22:00. Values are mean $\pm S D$ from 10 randomly selected plants.

intercellular $\mathrm{CO}_{2}$ concentration in the second leaf was 24.6$39.3 \%$ higher than the one in the first leaf at each time point (Figure 1D). The net photosynthetic rate reached the highest point at 10:00 and kept stable from 10:00 to 14:00, while it fell below zero at the other four time points, which means that the respiratory rate was greater than the photosynthetic rate at these time points (Figure 1A). Figure 1A also indicated that the photosynthetic rate was highest at mid-day (from 10:00 to 14:00), while the respiratory rate was highest at mid-night (2:00). There was an obvious high peak of transpiration rate in the daytime, which reached the highest point at 14:00, while there was a slight change-like sine wave from 18:00 to 6:00 (Figure 1B). Similarly, a high peak of stomatal conductance was observed in the daytime; however, the highest stomatal conductance was shown after 2:00 (Figure 1C). Conversely, the intercellular $\mathrm{CO}_{2}$ concentration during the nighttime was significantly higher than in the daytime, which displayed a low valley in the daytime. This concentration was lowest at 10:00, and kept stable from 10:00 to 14:00, while it increased and kept relatively constant during the night until 6:00 (Figure 1D).

\section{Natural Light/Dark Cycle Regulation of Carbon-Nitrogen Metabolites}

To study how carbon-nitrogen metabolites were regulated by the natural light/dark cycle, we analyzed the concentrations of chlorophyll, free ammonium and amino acids, soluble proteins, and carbohydrates in the rice shoots. Similar results were observed within the concentrations of chlorophyll, free ammonium, and soluble carbohydrates. The concentrations of chlorophyll a, chlorophyll $\mathrm{b}$, and chlorophyll $(\mathrm{a}+\mathrm{b})$ were relatively constant at the times of 2:00, 6:00, 10:00, 18:00, and 22:00, while there was a high peak at the time of 14:00 (Figure 2B). Compared to the other time points, at the time of 14:00, the concentration of chlorophyll a was $27.4-42.2 \%$ higher, the concentration of chlorophyll $b$ was $16.8-38.8 \%$ higher, and the concentration of chlorophyll $(\mathrm{a}+\mathrm{b})$ was $19.8-36.3 \%$ higher (Figure 2B). For the concentration of free ammonium, there were no significant changes between the first two time points (2:00 and 6:00), and between the last two time points (18:00 and 22:00) at nighttime, while significant changes were observed from 6:00 to 18:00 in the daytime (Figure 2C). The free ammonium concentration increased by 76.5 and $77.4 \%$ from $6: 00$ to $10: 00$ and from 10:00 to 14:00, respectively; and it decreased by $12.0 \%$ from 14:00 to 18:00 (Figure 2C). For the soluble carbohydrates, there were no significant changes between 22:00 to 2:00 during the night, while significant changes were observed from 6:00 to 22:00 (Figure 2D). The soluble carbohydrates increased by 26.8 and $71.8 \%$ from $6: 00$ to $10: 00$ and from $10: 00$ to $14: 00$, respectively, and kept stable from 14:00 to 18:00, then declined by $49.2 \%$ from 18:00 to 22:00 (Figure 2D).

However, the concentration of free amino acids and soluble proteins showed slight changes among the different time points during the entire day. The concentrations of free amino acids were relatively constant from the time of 2:00 to 22:00 and were slightly higher in the daytime than at nighttime (Figure 2E). Compared to nighttime, the average concentration of free amino 

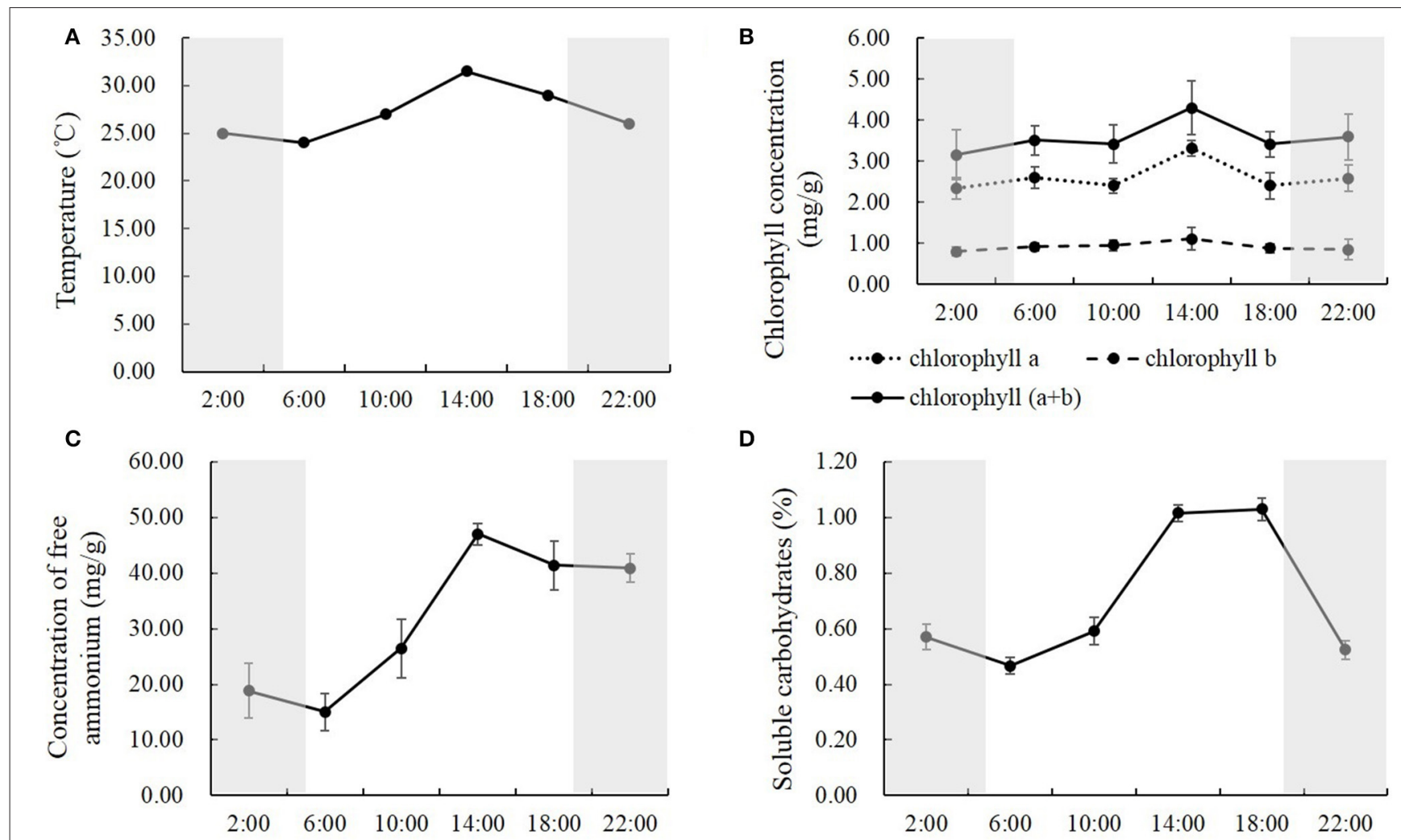

D
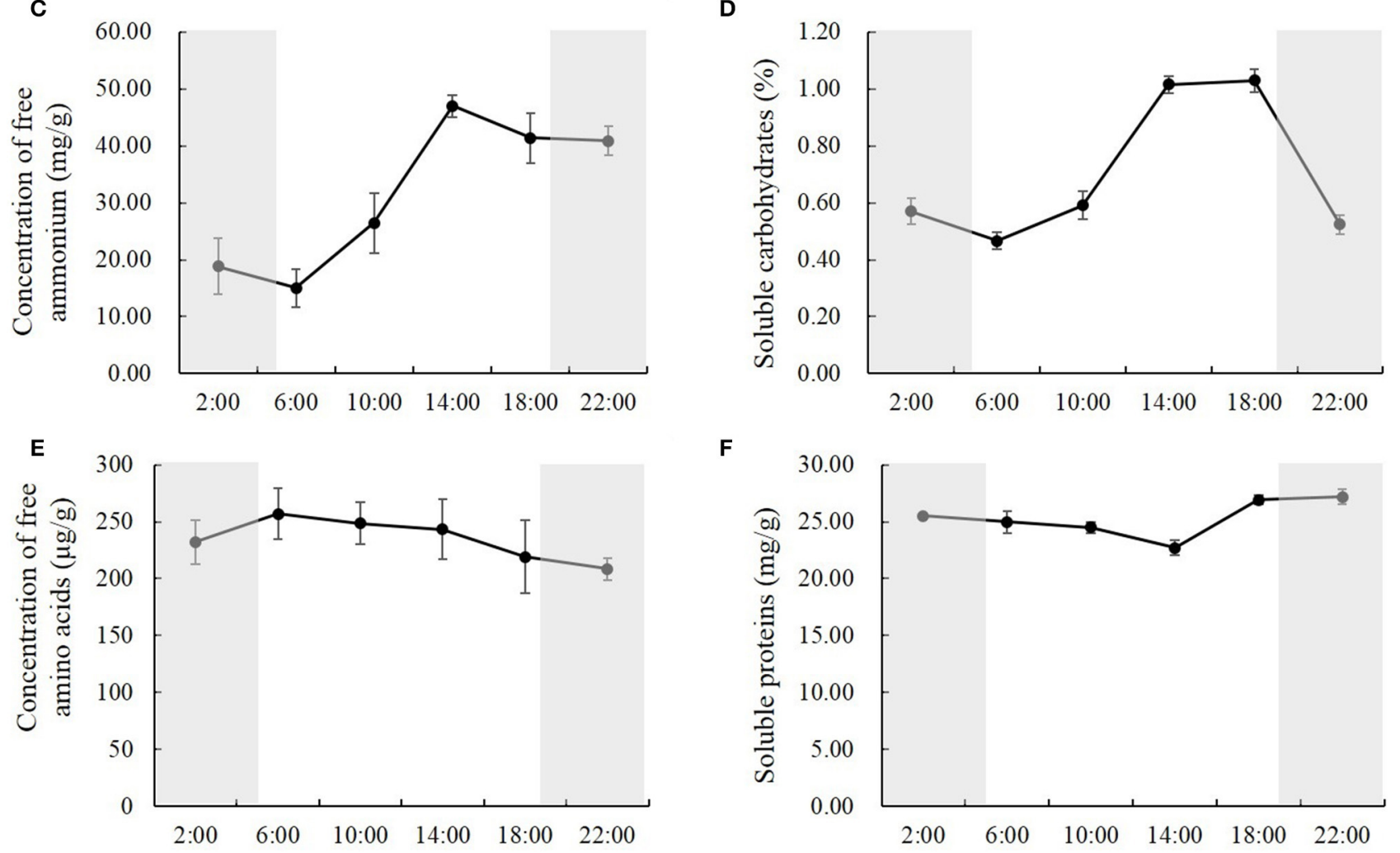

$\mathbf{F}$

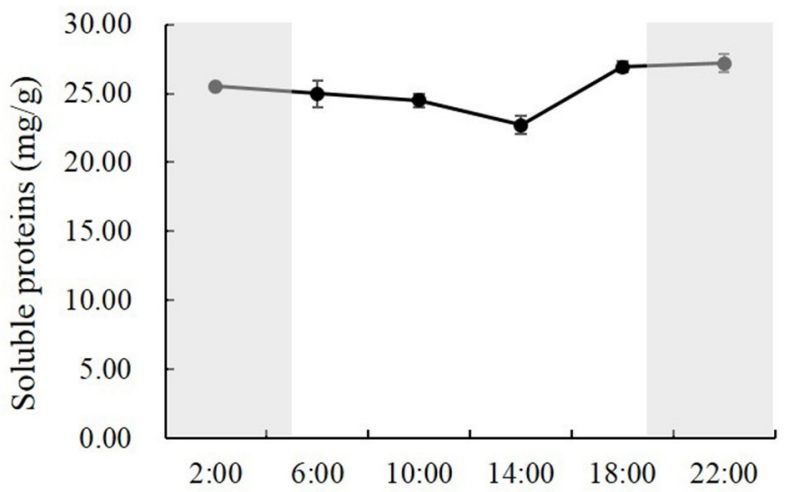

FIGURE 2 | The temperature (A), the concentrations of chlorophyll (B), free ammonium (C) and amino acids (E), soluble carbohydrates (D), and proteins $(\mathbf{F})$ in the rice shoots at the time of 2:00, 6:00, 10:00, 14:00, 18:00, and 22:00. Values are mean $\pm S D$ from three biological replicates.

acids in the daytime was $9.9 \%$ higher, and the highest one at 6:00 was $23.3 \%$ higher than the lowest one at 22:00 (Figure 2E). Opposite results were observed in the soluble proteins; they were slightly lower in the daytime than at night (Figure 2F).The average concentration of soluble proteins in the daytime was $6.0 \%$ lower than at night, and the lowest one at 14:00, was $16.5 \%$ lower than the highest one at 22:00 (Figure 2F).

\section{Natural Light/Dark Cycle Regulation of Nitrogen Metabolic Enzymes}

To study how nitrogen metabolic enzymes were regulated by the natural light/dark cycle, we analyzed the activities of nitrate reductase, glutamine synthetase, glutamate dehydrogenase and glutamate synthase in the rice shoots at the times of 2:00, $6: 00,10: 00,14: 00,18: 00$, and 22:00. Various, changing patterns were observed for the activities of nitrate reductase, glutamine synthetase, glutamate dehydrogenase, and glutamate synthase. For nitrate reductase, the activities changed significantly at the different time points, and the activities in the daytime were higher than those at night (Figure 3A). The nitrate reductase activity increased by 23.1 and $9.3 \%$ from 2:00 to $6: 00$ and from 6:00 to $10: 00$, respectively; and decreased by 24.8 and $19.1 \%$ from 10:00 to 14:00 and from 14:00 to 18:00, respectively; it kept relatively stable at the early part of the night (Figure 3A). There were no significant changes in glutamine synthetase activities at the different time points, except that it was the highest 

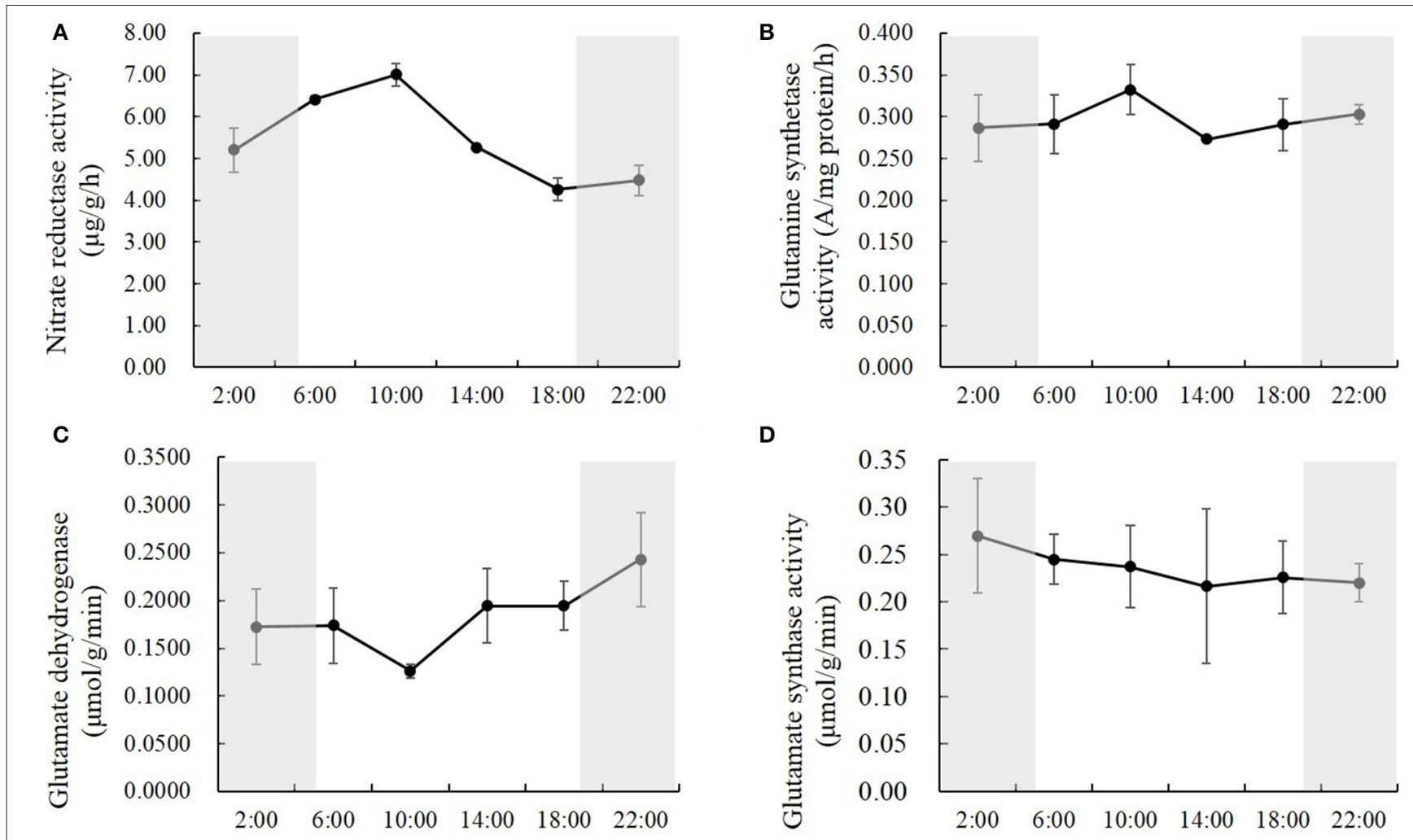

FIGURE 3 | The activities of nitrate reductase (A), glutamine synthetase (B), glutamate dehydrogenase (C), and glutamate synthase (D) in the rice shoots at the time of 2:00, 6:00, 10:00, 14:00, 18:00, and 22:00. Values are mean $\pm S D$ from three biological replicates.

at $10: 00$, which was $21.7 \%$ higher than the lowest reading (Figure 3B). The opposite result displayed in the glutamate dehydrogenase activity. There were no significant changes of glutamate dehydrogenase activities at the different time points, except that it was the lowest at 10:00, which was $48.1 \%$ lower than the highest one (Figure 3C). However, the glutamate synthase activities kept constant at all of the different time points (Figure 3D).

\section{Natural Light/Dark Cycle Regulation of Carbon-Nitrogen Metabolic Genes}

To study how gene expression responds to the natural light/dark cycle, the transcriptome was also analyzed in the rice shoots samples harvested at times: 2:00, 6:00, 10:00, 14:00, 18:00, and 22:00. A total of 397,173,322 high-quality reads (average length $=100 \mathrm{bp}$ ) were generated using an Illumina Hiseq 2000 sequencer (Supplementary Table S2). Each sample was represented by an average of 66.2 million reads, $\sim 98.3 \%$ of the reads could be mapped to the rice genome reference, and of these mapped reads, $\sim 95.0 \%$ mapped uniquely (Supplementary Table S2). Supplementary Figure S2 shows the reads mapped to individual chromosomes at each time point. Each sample was also represented by an average of 81.6 million mapped events, $\sim 87.8 \%$ of the events could be mapped to genes, and of these mapped events, $\sim 97.1 \%$ mapped to exons (Supplementary Table S3). Supplementary Figures S3,
S4 display the heat map and functional categories of these mapped genes, respectively. The eggnog functional category analysis revealed that more than $1 / 3(18.64+16.71 \%)$ of these genes were described to function unknown, or general function prediction only, more than $30 \%(9.21+7.87+$ $7.74+6.03 \%$ ) were described to DNA and protein regulation and signal transduction, $4.42 \%$ were described to carbohydrate transport and metabolism, and $3.53 \%$ were described to amino acid transport and metabolism (Supplementary Figure S4). Additionally, a total of 78,306 alternative splicing events have been found in our study, which could be divided into four groups: alternative $5^{\prime}$ donor sites $(10.73 \%)$, alternative $3^{\prime}$ acceptor sites $(19.88 \%)$, intron retention $(64.92 \%)$, and exon skipping (4.47\%) (Supplementary Figure S5). These alternative splicing events could be mapped to a total of 54,766 genes, $13.98 \%$ of these genes belong to the events of alternative $5^{\prime}$ donor sites, $24.27 \%$ belong to the events of alternative $3^{\prime}$ acceptor sites, $56.03 \%$ belong to the events of intron retention and $5.72 \%$ belong to the events of exon skipping (Supplementary Figure S5).

Compared to the mid-night time point (2:00), we obtained 146 (139 up- +7 down-regulated), 1958 (607 up- +1351 down-regulated), 1869 (696 up- +1173 down-regulated), 1453 (419 up- + 1034 down-regulated), and 321 (94 up- +227 down-regulated) differentially expressed genes at the times 6:00, 10:00, 14:00, 18:00, and 22:00, respectively (Figure 4A). Several randomly selected differentially expressed genes 


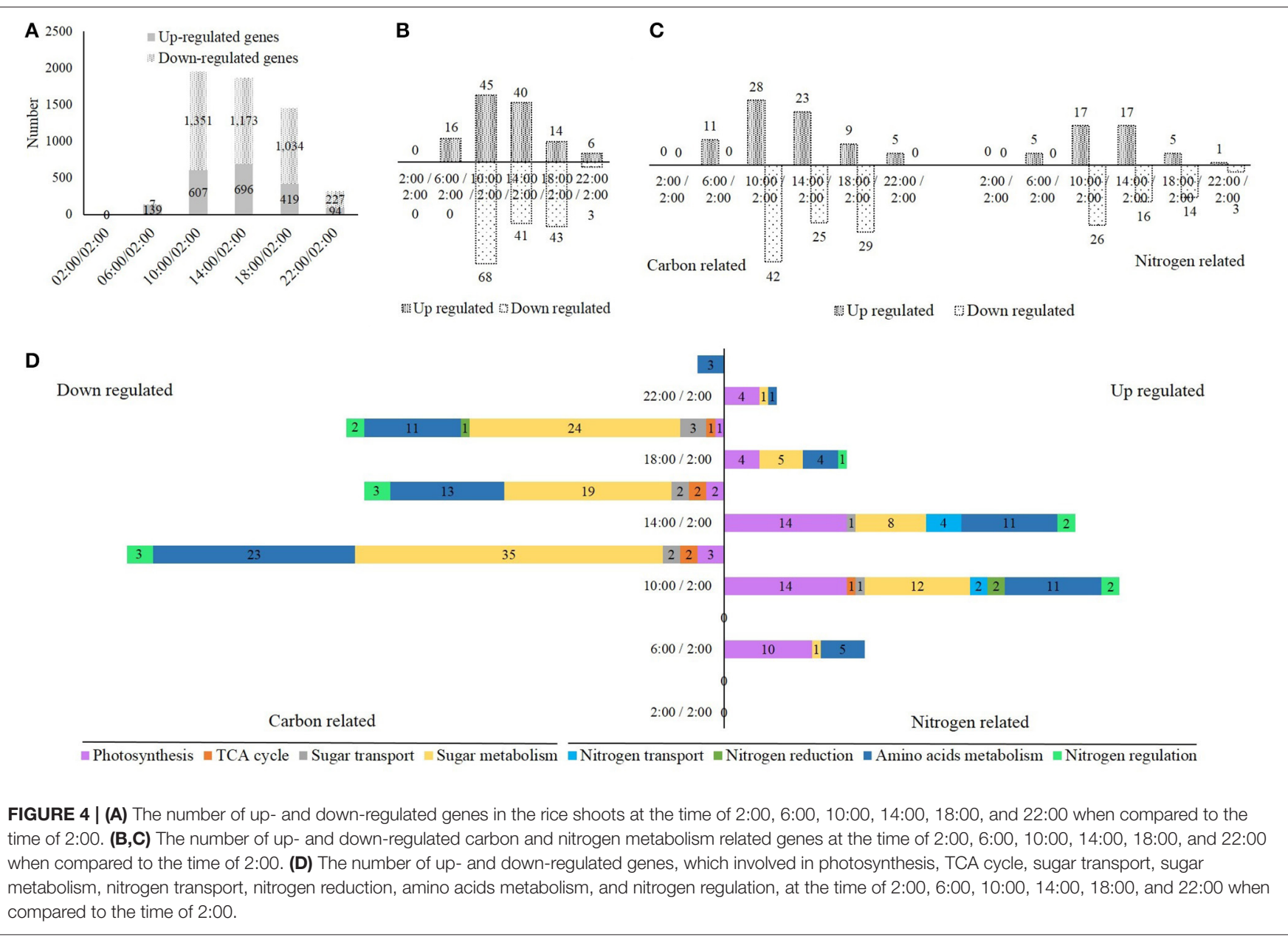

were also analyzed by qRT-PCR to validate the RNAseq results, and a close correlation was observed in this study (Supplementary Figure S6). Next, the carbon and nitrogen metabolism-related differentially expressed genes were selected for further analysis. We obtained 16 (16 up-regulated), 113 (45 up- +68 down-regulated), 81 (40 up- +41 down-regulated), 54 (14 up- +43 down-regulated), and 9 ( 6 up- +3 down-regulated) carbon and nitrogen metabolic differentially expressed genes at the times of $6: 00,10: 00,14: 00,18: 00$, and 22:00, respectively (Figure 4B). The number of these differentially expressed genes was highest at 10:00, and declined gradually from 14:00 to 22:00, which closely correlated to the light and temperature (Figures 4A,B). More down-regulated genes than up-regulated genes and more carbon-related genes than nitrogen-related genes were observed (Figures $\mathbf{4 B}, \mathbf{C}$ ). Additionally, we divided these carbon and nitrogen metabolic differentially expressed genes into eight groups: photosynthesis, TCA cycle, sugar transport, sugar metabolism, nitrogen transport, nitrogen reduction, amino acids metabolism, and nitrogen regulation (Figure 4D). For down-regulated genes, most were involved in the sugar and amino acid metabolism, while for up-regulated genes, most were involved in the photosynthesis, sugar, and amino acid metabolism (Figure 4D). We also listed these carbon and nitrogen metabolic differentially expressed genes at each time point in Tables $\mathbf{1 - 5}$.

\section{Natural Light/Dark Cycle Regulation of Carbon-Nitrogen Related miRNAs and Their Target Genes}

Additionally, the miRNAs were analyzed in the samples of rice shoots harvested at the times of 2:00, 6:00, 10:00, 14:00, 18:00, and 22:00. A total of 38,704,070 high-quality clean reads (15-30 nt) were generated using an Illumina Hiseq 2000 sequencer, and each sample was represented by an average of 6.5 million reads (Supplementary Table S4). Analysis of the size distribution of unique sequences showed that $24 \mathrm{nt}$ long RNAs were the most abundant, followed by 23, 21, 22, and 25 nt long RNAs (Supplementary Figure S7). Figure 5A displays the annotations of total and unique sequences, which were blasted with non-coding RNAs in the database of Rfam (11.0). For unique sequences, more than $1 / 3$ sRNA sequences matched rRNAs, followed by miRNAs (10\%), tRNAs (8\%), and snoRNAs (7\%) (Figure 5A). By blasting with rice references in miRBase, we have detected a total of 2038 mature miRNAs, and each sample was represented by an average of 340 mature 
TABLE 1 | Differentially expressed genes involved in carbon and nitrogen metabolism at the time of 6:00 compared to 2:00.

\begin{tabular}{|c|c|c|c|c|c|}
\hline & ID number & Gene annotation & $\begin{array}{c}\text { Base mean } \\
6: 00\end{array}$ & $\begin{array}{c}\text { Base mean } \\
\text { 2:00 }\end{array}$ & $\begin{array}{c}\text { Fold change } \\
(6: 00 / 2: 00)\end{array}$ \\
\hline \multicolumn{6}{|l|}{ CARBON RELATED } \\
\hline \multirow[t]{10}{*}{ Photosynthesis } & OS04G0414700 & PsaO; photosystem I subunit PsaO & 20251.84 & 824.87 & 24.55 \\
\hline & OS06G0320500 & LHCA1; light-harvesting complex I chlorophyll a/b binding protein 1 & 21176.03 & 1192.63 & 17.76 \\
\hline & OS02G0197600 & LHCA3; light-harvesting complex I chlorophyll a/b binding protein 3 & 48958.24 & 1555.22 & 31.48 \\
\hline & OS08G0435900 & LHCA4; light-harvesting complex I chlorophyll a/b binding protein 4 & 47573.59 & 1240.63 & 38.35 \\
\hline & OS01G0600900 & LHCB1; light-harvesting complex II chlorophyll a/b binding protein 1 & 25126.92 & 897.98 & 27.98 \\
\hline & OS09G0346500 & LHCB1; light-harvesting complex II chlorophyll a/b binding protein 1 & 17529.23 & 200.13 & 87.59 \\
\hline & OS03G0592500 & LHCB2; light-harvesting complex II chlorophyll a/b binding protein 2 & 29101.71 & 466.71 & 62.36 \\
\hline & OS07G0562700 & LHCB3; light-harvesting complex II chlorophyll a/b binding protein 3 & 15376.76 & 655.02 & 23.48 \\
\hline & OS11G0242800 & LHCB5; light-harvesting complex II chlorophyll a/b binding protein 5 & 36926.38 & 1932.58 & 19.11 \\
\hline & OS04G0457000 & LHCB6; light-harvesting complex II chlorophyll a/b binding protein 6 & 24346.09 & 1030.90 & 23.62 \\
\hline TCA cycle & - & & & & \\
\hline Sugar transport & - & & & & \\
\hline Sugar metabolism & OS05G0366600 & Beta-glucosidase 22 & 8012.55 & 409.85 & 19.55 \\
\hline \multicolumn{6}{|l|}{ NITROGEN RELATED } \\
\hline Nitrogen transport & - & & & & \\
\hline Nitrogen reduction & - & & & & \\
\hline \multirow[t]{5}{*}{ Amino acids metabolism } & OS09G0424200 & Glutamine synthetase-like protein & 198.74 & 4.43 & 44.85 \\
\hline & OS03G0231600 & Branched-chain amino acid aminotransferase & 3405.72 & 130.71 & 26.06 \\
\hline & OS12G0434400 & CARP, pepA; leucyl aminopeptidase & 40.18 & 0.74 & 54.41 \\
\hline & OS03G0283000 & GST; glutathione S-transferase & 130.32 & 1.48 & 88.24 \\
\hline & OS05G0148900 & GST; glutathione S-transferase & 180.28 & 5.17 & 34.88 \\
\hline Nitrogen regulation & - & & & & \\
\hline
\end{tabular}

miRNAs (Supplementary Table S5). Supplementary Figure S8 displays the heat map of these mature miRNAs at each time point. When compared to the mid-night time point (2:00), we obtained differentially expressed mature miRNAs at the times of 6:00, 10:00, 14:00, 18:00, and 22:00, respectively (Figures 5B-F). Compared to the other time points, the variation of the mature miRNAs expression levels was greatest at the time of 10:00 (Figure 5C).

Additionally, we analyzed the target genes of these mature miRNAs by psRNATarget. Next, we selected four carbon and nitrogen metabolism related miRNAs: osa-miR1440b, osamiR2876-5p, osa-miR1877, and osa-miR5799, as they targeted the carbon and nitrogen metabolic differentially expressed genes, which are listed in Tables 1-5. Osa-miR1440b targeted the gene of inositol-1,3,4-trisphosphate 5/6-kinase/inositoltetrakisphosphate 1-kinase (OS03G0726200), osa-miR2876-5p targeted the gene of chitinase 6 (OS02G0605900), osa-miR1877 targeted the gene of glutamate receptor (OS02G0787600), and osa-miR5799 targeted the gene of mannose-1-phosphate guanylyltransferase (OS03G0268400). Figure 6 shows the expression levels of osa-miR1440b, osa-miR2876-5p, osamiR1877, osa-miR5799, and their target genes at each time points. The expression level analysis showed that the four carbon and nitrogen metabolis-related miRNAs negatively regulated their target genes at most of the time points (Figure 6). The same expression patterns of osa-miR1440b and osa-miR2876-5p target genes were observed; i.e., that they highly expressed at 10:00 and lowly expressed at other time points (Figures 6A,B).
Conversely, the target gene of osa-miR5799 highly expressed at 2:00 and 22:00, expressed in the middle level at 6:00, 14:00, and 18:00, and expressed at the bottom level at 10:00 (Figure 6D). Additionally, the target gene of osa-miR1877 expressed highly at both 10:00 and 18:00, and expressed lowest at the other time points (Figure 6C). From the psRNATarget database, we found that these four carbon and nitrogen metabolism- related miRNAs also targeted several other genes (Supplementary Table S6).

\section{DISCUSSION}

For a notably long time, studies have focused on the analysis of circadian clock transgenic lines and mutants under artificially controlled light/dark conditions. The results clearly implied that the plant circadian clock influenced photosynthesis, growth and fitness as well as the primary metabolism, especially carbon metabolism (Green et al., 2002; Dodd et al., 2005; Yerushalmi et al., 2011). Generally, plants grow under the natural diurnal condition, where the temperature and light are dramatically changing and interacting with each other. However, little is known about the natural light/dark cycle regulation of plant metabolism and gene regulation. As cellular carbon and nitrogen metabolism must be tightly coordinated, in this paper, we focused on the natural light/dark cycle regulation of carbon and nitrogen metabolism, carbon and nitrogen related gene expression and miRNAs in rice. 
TABLE 2 | Differentially expressed genes involved in carbon and nitrogen metabolism at the time of 10:00 compared to 2:00.

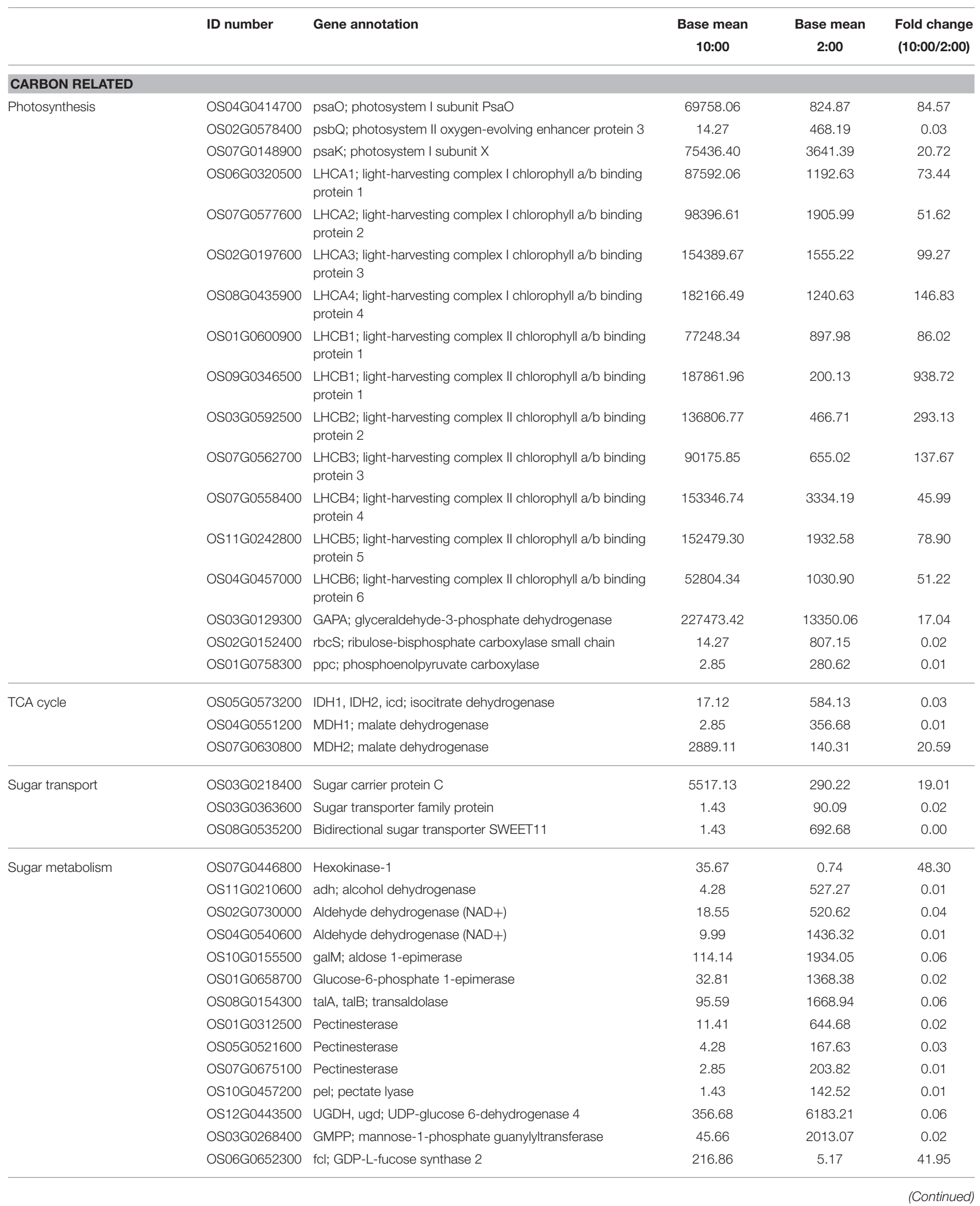




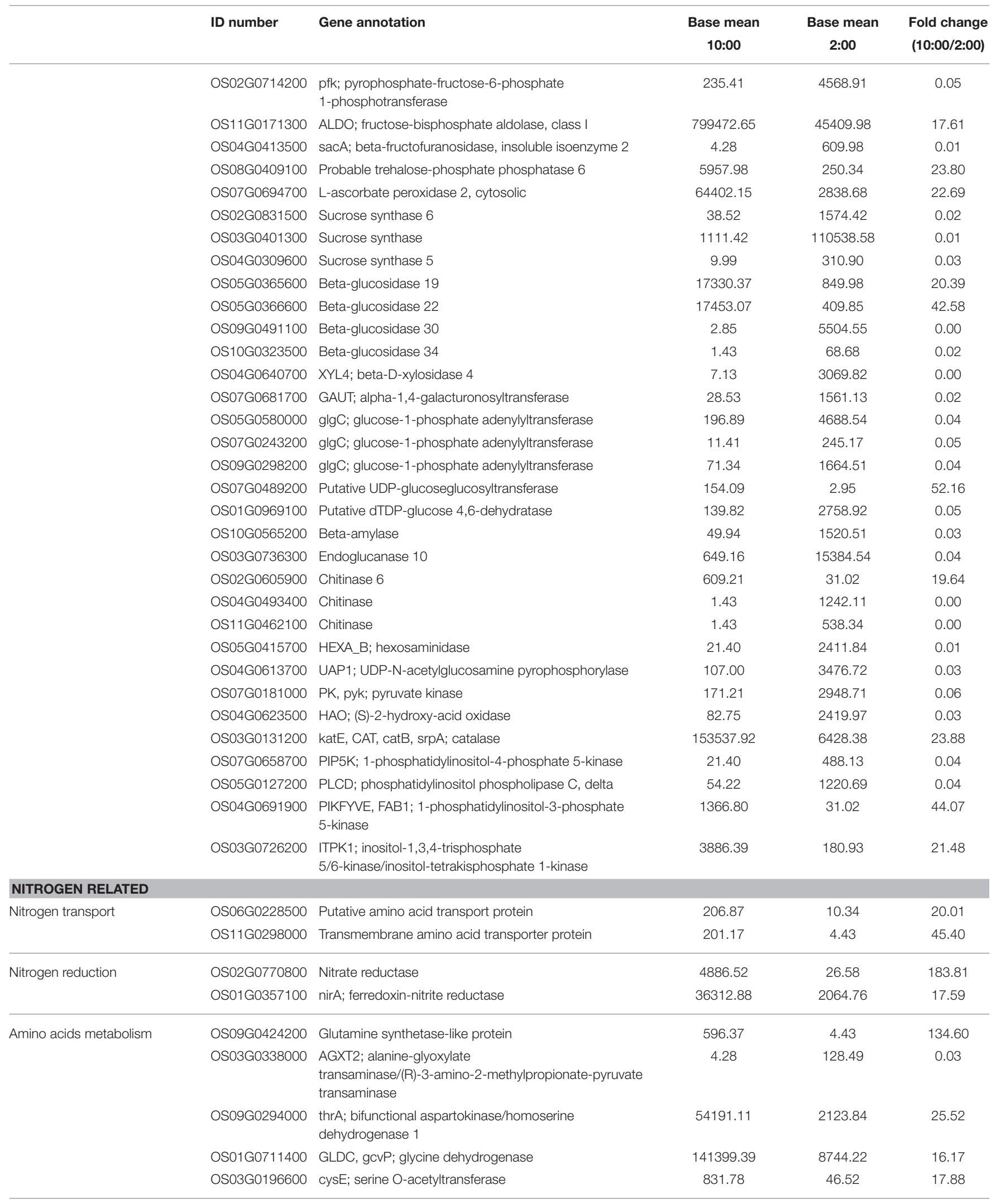




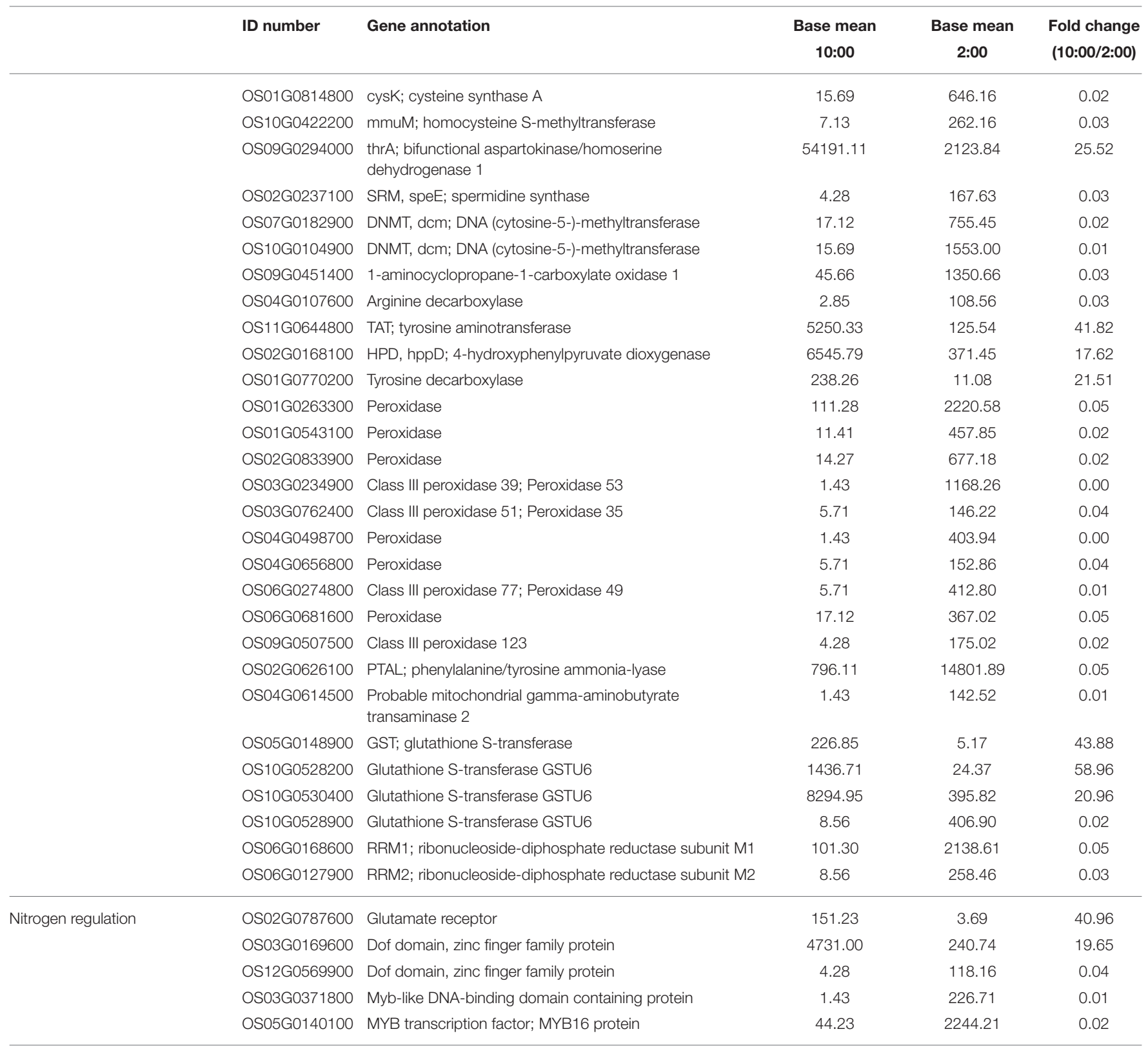

Plants are photoautotrophs, which produce sugars from photosynthesis to ensure plant growth and development. It has been reported that photosynthesis is under circadian regulation in Arabidopsis and Brassica rapa. Compared to $24 \mathrm{~h}$ period cycles, more $\mathrm{CO}_{2}$ was fixed in Arabidopsis leaves grown under $28 \mathrm{~h}$ period cycles (Graf et al., 2010; Graf and Smith, 2011). Edwards et al. (2011) reported that photosynthesis rate, transpiration rate and stomatal conductance were significantly correlated with circadian period in Brassica rapa. In our study, the net photosynthetic rate, respiratory rate, stomatal conductance, and intercellular $\mathrm{CO}_{2}$ concentration were also regulated by the natural light/dark cycle. Similar regulatory patterns were shown in the net photosynthetic rate, respiratory rate, and stomatal conductance, such that an obvious high peak was observed in the daytime. However, the opposite regulatory pattern was shown in the intercellular $\mathrm{CO}_{2}$ concentration, which indicated that more $\mathrm{CO}_{2}$ was fixed into carbohydrates by a high photosynthetic rate in the daytime.

Metabolism is a crucial circadian output, which can ensure plants' optimal physiology, growth and behavior under the natural diurnal condition (Dodd et al., 2005; Turek et al., 2005). Metabolomics analysis has detected that $\sim 30 \%$ of measured primary metabolites were under the regulation of circadian oscillations (Espinoza et al., 2010). Starch synthesis and degradation are important aspects of carbon metabolism in plants that are regulated by the circadian clock. Graf and 
TABLE 3 | Differentially expressed genes involved in carbon and nitrogen metabolism at the time of 14:00 compared to 2:00.

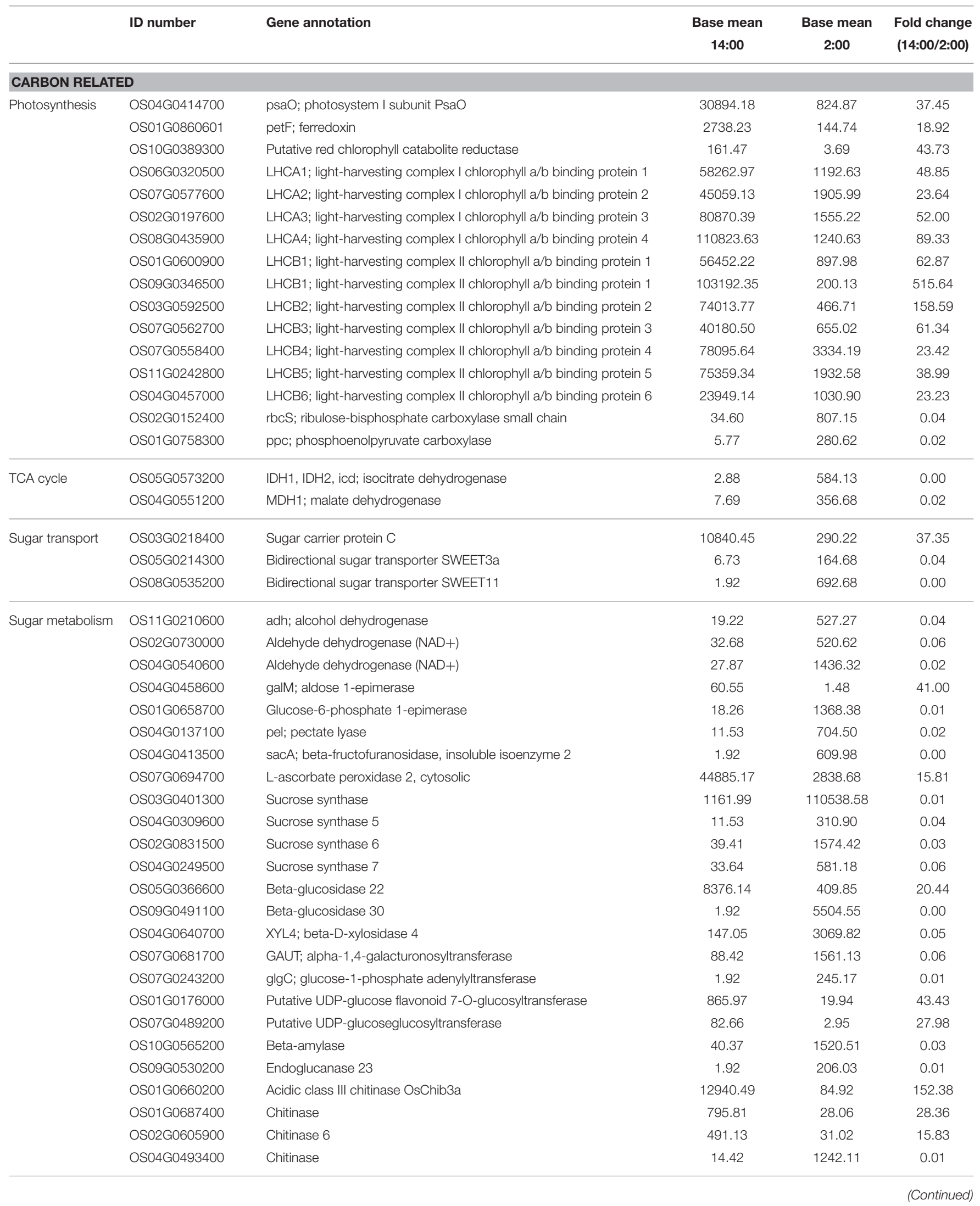


TABLE 3 | Continued

\begin{tabular}{|c|c|c|c|c|c|}
\hline & ID number & Gene annotation & $\begin{array}{c}\text { Base mean } \\
14: 00\end{array}$ & $\begin{array}{c}\text { Base mean } \\
2: 00\end{array}$ & $\begin{array}{l}\text { Fold change } \\
(14: 00 / 2: 00)\end{array}$ \\
\hline & OS05G0399400 & Chitinase & 2.88 & 923.09 & 0.00 \\
\hline & OS05G0415700 & HEXA_B; hexosaminidase & 4.81 & 2411.84 & 0.00 \\
\hline \multicolumn{6}{|c|}{ NITROGEN RELATED } \\
\hline \multirow[t]{4}{*}{ Nitrogen transport } & OS03G0838400 & Ammonium transporter 3 member 2 & 2370.12 & 36.92 & 64.19 \\
\hline & OS02G0550800 & Ammonium transporter 3 member 3 & 1521.45 & 49.48 & 30.75 \\
\hline & OS01G0209800 & Putative amino acid permease & 622.80 & 28.80 & 21.62 \\
\hline & OS08G0127100 & Putative histidine amino acidtransporter & 14278.37 & 321.23 & 44.45 \\
\hline Nitrogen reduction & - & & & & \\
\hline \multirow{24}{*}{$\begin{array}{l}\text { Amino acids } \\
\text { metabolism }\end{array}$} & OS09G0424200 & Glutamine synthetase-like protein & 157.62 & 4.43 & 35.57 \\
\hline & OS03G0236200 & gadB, gadA, GAD; glutamate decarboxylase & 629.53 & 19.20 & 32.79 \\
\hline & OS10G0422200 & mmuM; homocysteine S-methyltransferase & 9.61 & 262.16 & 0.04 \\
\hline & OS02G0237100 & SRM, speE; spermidine synthase & 0.96 & 167.63 & 0.01 \\
\hline & OS10G0104900 & DNMT, dcm; DNA (cytosine-5-)-methyltransferase & 11.53 & 1553.00 & 0.01 \\
\hline & OS03G0106400 & ilvE; branched-chain amino acid aminotransferase & 7.69 & 181.66 & 0.04 \\
\hline & OS07G0638400 & PRDX6; peroxiredoxin 6, 1-Cys peroxiredoxin & 127.83 & 1.48 & 86.55 \\
\hline & OS01G0263300 & Peroxidase & 30.76 & 2220.58 & 0.01 \\
\hline & OS01G0543100 & Peroxidase & 13.46 & 457.85 & 0.03 \\
\hline & OS02G0833900 & Peroxidase & 7.69 & 677.18 & 0.01 \\
\hline & OS03G0234900 & Class III peroxidase 39; Peroxidase 53 & 69.20 & 1168.26 & 0.06 \\
\hline & OS04G0656800 & Peroxidase & 4.81 & 152.86 & 0.03 \\
\hline & OS05G0499300 & Peroxidase 1 & 1.92 & 585.61 & 0.00 \\
\hline & OS06G0695500 & Class III peroxidase 90 & 31.72 & 943.03 & 0.03 \\
\hline & OS09G0507500 & Class III peroxidase 123 & 1.92 & 175.02 & 0.01 \\
\hline & OS02G0626600 & Phenylalanine ammonia-lyase & 100.92 & 3.69 & 27.33 \\
\hline & OS08G0448000 & 4-coumarate-CoA ligase & 448.84 & 22.15 & 20.26 \\
\hline & OS12G0434400 & CARP, pepA; leucyl aminopeptidase & 42.29 & 0.74 & 57.27 \\
\hline & OS01G0372400 & GST, gst; glutathione S-transferase & 187.42 & 5.91 & 31.72 \\
\hline & OS03G0283000 & GST, gst; glutathione S-transferase & 363.30 & 1.48 & 245.98 \\
\hline & OS09G0467200 & GST, gst; glutathione S-transferase & 9561.20 & 626.96 & 15.25 \\
\hline & OS10G0527800 & GST, gst; glutathione S-transferase & 1372.48 & 47.26 & 29.04 \\
\hline & OS10G0528100 & GST, gst; glutathione S-transferase & 577.63 & 7.38 & 78.22 \\
\hline & OS06G0127900 & RRM2; ribonucleoside-diphosphate reductase subunit M2 & 13.46 & 258.46 & 0.05 \\
\hline \multirow[t]{5}{*}{ Nitrogen regulation } & OS02G0787600 & Glutamate receptor & 535.34 & 3.69 & 144.99 \\
\hline & OS03G0169600 & Dof domain, zinc finger family protein & 3593.62 & 240.74 & 14.93 \\
\hline & OS12G0569900 & Dof domain, zinc finger family protein & 4.81 & 118.16 & 0.04 \\
\hline & OS01G0229000 & MYB23 protein & 18.26 & 618.84 & 0.03 \\
\hline & OS05G0140100 & MYB transcription factor; MYB16 protein & 88.42 & 2244.21 & 0.04 \\
\hline
\end{tabular}

Smith (2011) reported that starch degraded into sucrose, Suc6P (sucrose 6-phosphate), and Tre6P (trehalose 6-phosphate) at night in Arabidopsis, and sucrose arrived at a peak level in the morning, which was necessary to prevent sugar shortage and growth penalties at night. Significant correlations were also found in the day and nighttime between growth rates and the levels of Tre6P and shikimate, which is an intermediate in amino acid biosynthesis that may act as a read-out for amino acid biosynthesis (Seaton et al., 2014). Tre6P has been reported to inhibit SnRK1 (SNF1-related protein kinases 1), which provides a pathway to promote protein synthesis when sugars are high (Zhang et al., 2009; Paul et al., 2010; Nunes et al., 2013). In our study, there was a synchronic association between the temperature/light and the concentrations of chlorophyll a and soluble carbohydrates. However, the concentration of free amino acids and soluble proteins showed slight changes among the different time points during the entire day. These results suggest that higher temperature and light intensity in the mid-day promote carbon fixation, not protein synthesis. Additionally, a dramatic increase of free ammonium concentration and nitrate 
TABLE 4 | Differentially expressed genes involved in carbon and nitrogen metabolism at the time of 18:00 compared to 2:00.

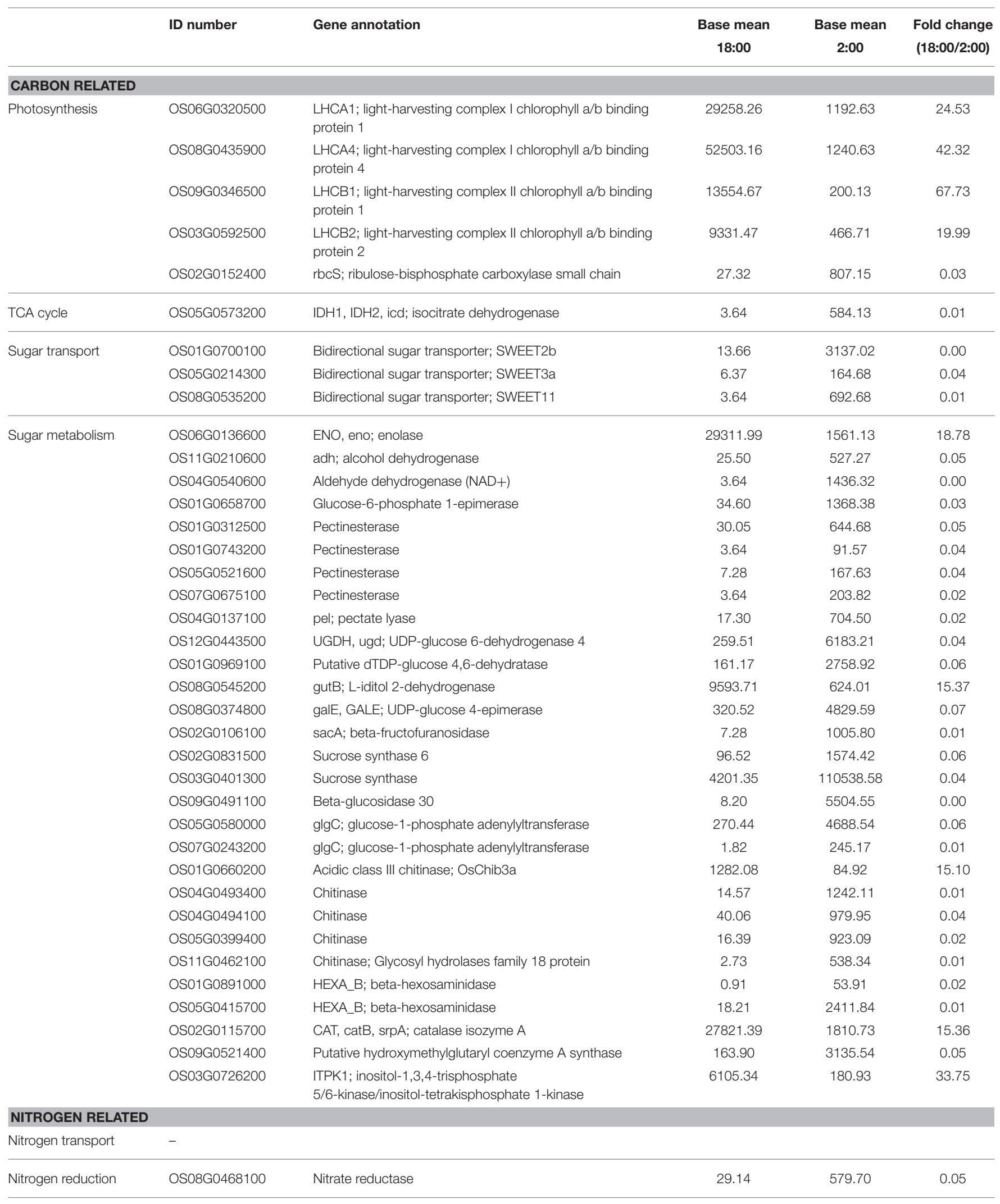


TABLE 4 | Continued

\begin{tabular}{|c|c|c|c|c|c|}
\hline & ID number & Gene annotation & $\begin{array}{c}\text { Base mean } \\
18: 00\end{array}$ & $\begin{array}{c}\text { Base mean } \\
2: 00\end{array}$ & $\begin{array}{l}\text { Fold change } \\
(18: 00 / 2: 00)\end{array}$ \\
\hline \multirow[t]{9}{*}{ Amino acids metabolism } & OS05G0555600 & Glutamate synthase 2 [NADH], chloroplastic & 3342.68 & 27.32 & 122.34 \\
\hline & OS10G0104900 & DNMT, dcm; DNA (cytosine-5-)-methyltransferase & 5.46 & 1553.00 & 0.00 \\
\hline & OS03G0106400 & ilvE; branched-chain amino acid aminotransferase & 7.28 & 181.66 & 0.04 \\
\hline & OS03G0234900 & Class III peroxidase 39; Peroxidase 53 & 40.98 & 1168.26 & 0.04 \\
\hline & OS04G0498700 & Peroxidase & 0.91 & 403.94 & 0.00 \\
\hline & OS04G0656800 & Peroxidase & 0.91 & 152.86 & 0.01 \\
\hline & OS05G0499300 & Peroxidase 1 & 13.66 & 585.61 & 0.02 \\
\hline & OS10G0536700 & Class III peroxidase 128 & 11.84 & 252.56 & 0.05 \\
\hline & OS06G0127900 & RRM2; ribonucleoside-diphosphate reductase subunit M2 & 6.37 & 258.46 & 0.02 \\
\hline \multirow[t]{3}{*}{ Nitrogen regulation } & OS02G0787600 & Glutamate receptor & 124.75 & 3.69 & 33.79 \\
\hline & OS12G0569900 & Dof domain, zinc finger family protein & 0.91 & 118.16 & 0.01 \\
\hline & OS01G0229000 & MYB23 protein & 21.85 & 618.84 & 0.04 \\
\hline
\end{tabular}

TABLE 5 | Differentially expressed genes involved in carbon and nitrogen metabolism at the time of 22:00 compared to 2:00.

\begin{tabular}{|c|c|c|c|c|c|}
\hline & ID number & Gene annotation & $\begin{array}{c}\text { Base mean } \\
22: 00\end{array}$ & $\begin{array}{c}\text { Base mean } \\
\text { 2:00 }\end{array}$ & $\begin{array}{l}\text { Fold change } \\
(22: 00 / 2: 00)\end{array}$ \\
\hline \multicolumn{6}{|l|}{ CARBON RELATED } \\
\hline \multirow[t]{3}{*}{ Photosynthesis } & OS12G0207500 & ATPF1B, atpD; F-type $\mathrm{H}+$-transporting ATPase subunit beta & 89.68 & 2.22 & 40.48 \\
\hline & OS05G0427800 & rbcL; ribulose-bisphosphate carboxylase large chain & 64.77 & 1.48 & 43.85 \\
\hline & OS10G0356000 & rbcL; rRibulose bisphosphate carboxylase large chain & 5478.44 & 110.03 & 49.79 \\
\hline TCA cycle & - & & & & \\
\hline Sugar transport & - & & & & \\
\hline Sugar metabolism & OS07G0446800 & Hexokinase-1 & 205.27 & 0.74 & 277.96 \\
\hline \multicolumn{6}{|l|}{ NITROGEN RELATED } \\
\hline \multirow[t]{4}{*}{ Amino acids metabolism } & OS07G0182900 & DNMT, dcm; DNA (cytosine-5-)-methyltransferase & 29.89 & 755.45 & 0.04 \\
\hline & OS10G0104900 & DNMT, dcm; DNA (cytosine-5-)-methyltransferase & 19.93 & 1553.00 & 0.01 \\
\hline & OS07G0677300 & Peroxidase 2 & 1.00 & 281.36 & 0.00 \\
\hline & OS02G0626600 & Phenylalanine ammonia-lyase & 324.84 & 3.69 & 87.98 \\
\hline
\end{tabular}

reductase activity were observed in the daytime, while the activities of glutamine synthetase, glutamate dehydrogenase, and glutamate synthase were slightly changed during the whole day. These results also suggest that the protein synthesis is not significantly facilitated by the light and temperature, although high levels of the free ammonium and carbohydrates were exhibited in the day time.

It has been reported that at least $30 \%$ of the genome transcripts are under circadian regulation (Harmer et al., 2000; Covington et al., 2008; Michael et al., 2008; Chow and Kay, 


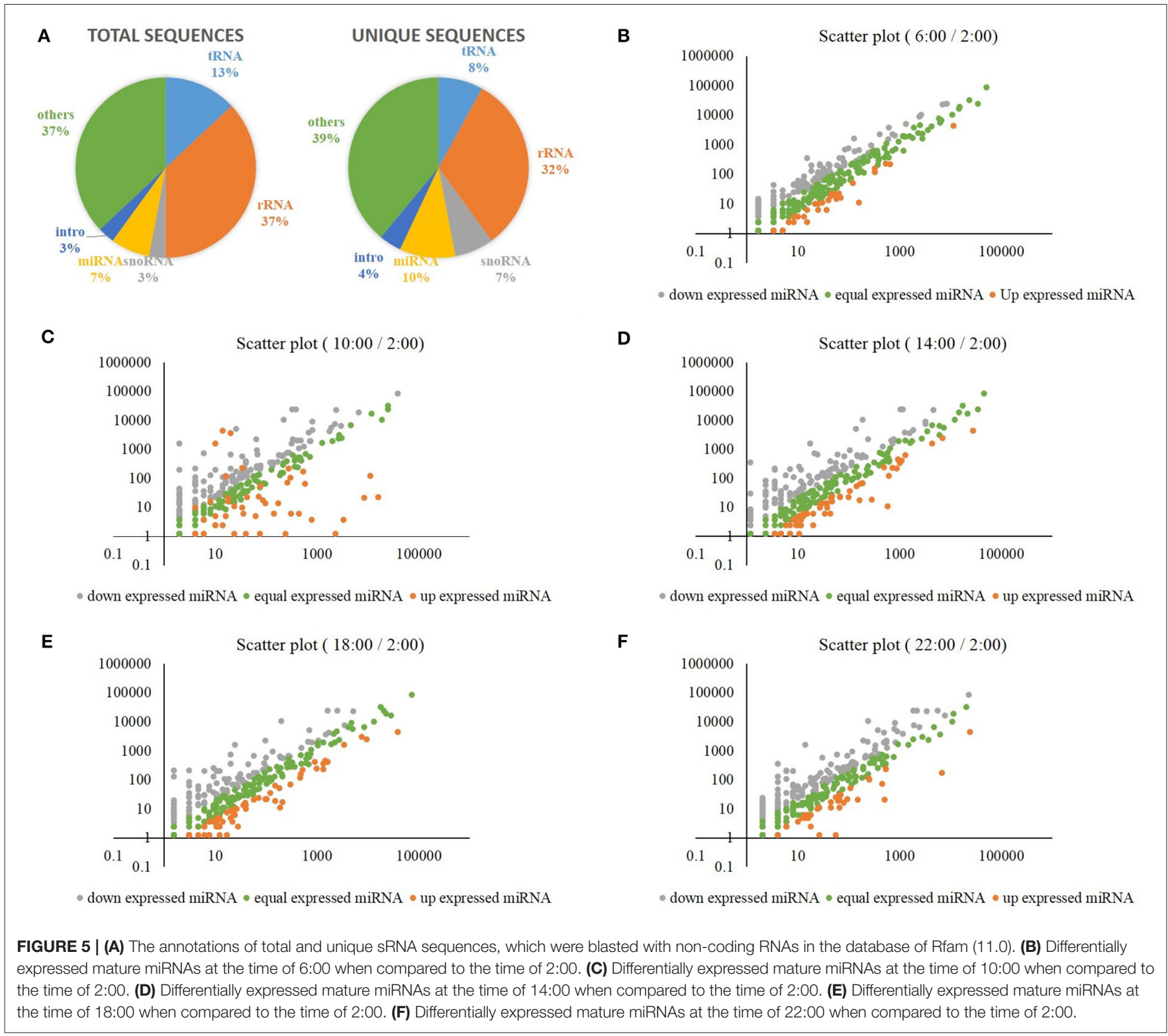

2013). Transcriptome analysis in Arabidopsis demonstrated the circadian regulation of key transcripts involved in photosynthesis and starch metabolism, isoprenoid (chlorophyll and carotene) biosynthesis, phenylpropanoid (flavonoid and anthocyanin) biosynthesis, redox balance and the membrane transport associated with nitrogen, sulfur and sugar (Dodd et al., 2005; Lu et al., 2005; Gutiérrez et al., 2008; Graf et al., 2010; Kerwin et al., 2011; Lai et al., 2012). In our study, the transcriptome was also analyzed in the samples of rice shoots harvested at the times of 2:00,6:00, 10:00, 14:00, 18:00, and 22:00, to study how gene expression responds to the natural light/dark cycle. When compared to the middle-of-night time point (2:00), we obtained a large amount of differentially expressed genes at the times of 6:00, 10:00, 14:00, 18:00, and 22:00. Later, we focused on the analysis of carbon and nitrogen metabolism- related differentially expressed genes, which were divided into eight groups: photosynthesis, TCA cycle, sugar transport, sugar metabolism, nitrogen transport, nitrogen reduction, amino acid metabolism, and nitrogen regulation. Most of the down-regulated genes were involved in the sugar and amino acid metabolism, while most of the up-regulated genes were involved in the photosynthesis, sugar, and amino acid metabolism.

Post-transcriptional regulation can result in rapid and durable responses to the environmental light and temperature. The first evidence showing the importance of post-transcriptional regulation in maintaining circadian rhythmicity was discovered in the single-celled green algae, Acetabularia, which could survive for several weeks after removing its nucleus, and continue to photosynthesize rhythmically in constant light (Mergenhagen and Schweiger, 1975; Lakin-Thomas, 2006). Alternative pre-mRNA splicing and miRNA regulation are two 

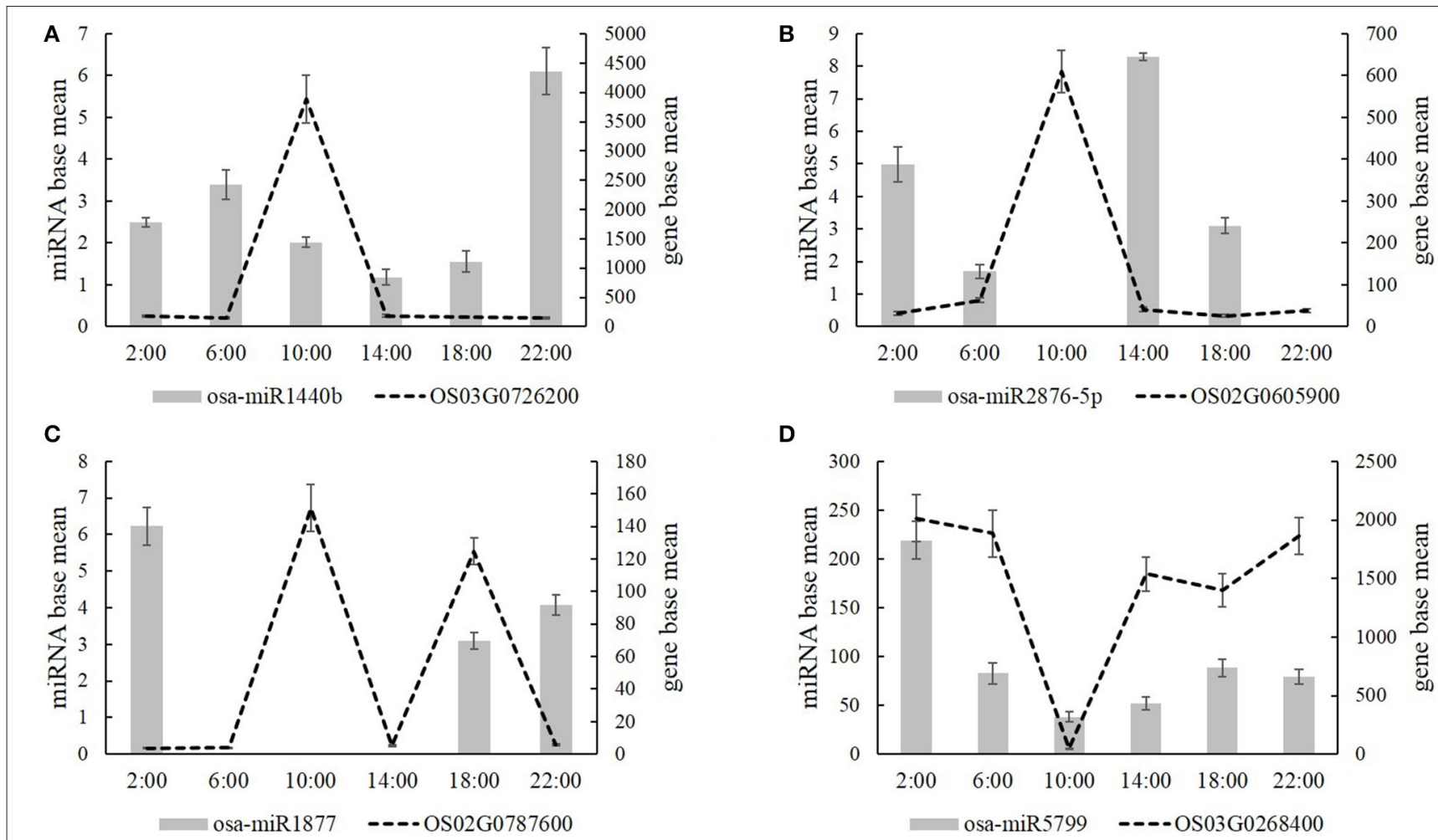

D

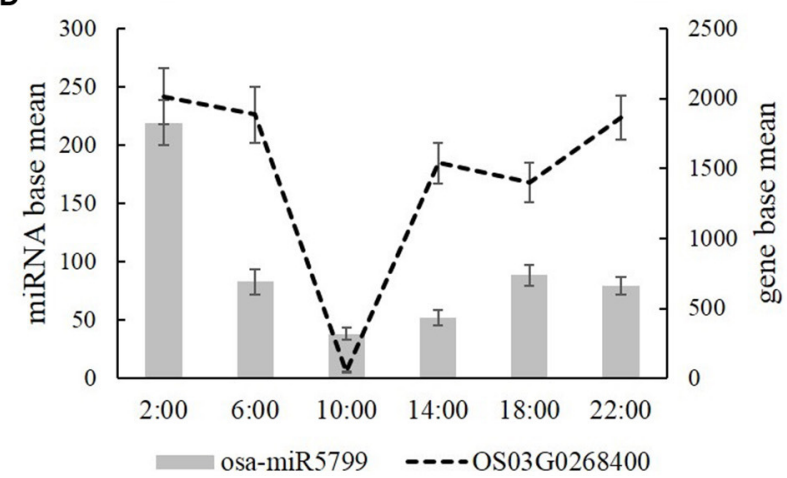

FIGURE 6 | The expression level of four carbon and nitrogen metabolism related miRNAs (A, Osa-miR1440b; B, osa-miR2876-5p; C, osa-miR1877; D, osa-miR5799) and their target genes at the time of 2:00, 6:00, 10:00, 14:00, 18:00, and 22:00. Values are mean $\pm S D$ from three biological replicates.

processes that mediate most post-transcriptional regulation in response to environmental changes (Bartok et al., 2013). Recent studies demonstrated the importance of alternative splicing in mediating responses of circadian clock to temperature changes in Arabidopsis using a genome-wide approach (Bieniawska et al., 2008; Staiger and Green, 2011; James et al., 2012). The results revealed the extensive changes in the splicing of many clock genes. For example, a temperature-sensitive alternative splicing event involving intron retention in CCA1 mRNA was identified in Arabidopsis (Gould et al., 2006; Filichkin et al., 2010). It has also been reported that this alternative splicing regulation was present not only in Arabidopsis thaliana but also in Oryza sativa, Brachypodiumdistachyon and Populustrichocarpa, mono, and di-cotyledonous species that diverged from a common ancestor 120-170 million years ago (Lynch and Conery, 2000; Tuskan et al., 2006). In our study, a total of 78,306 alternative splicing events have been found at each time point, which mainly belong to alternative $5^{\prime}$ donor sites, alternative $3^{\prime}$ acceptor sites, intron retention, and exon skipping. Additionally, there has been a growing awareness of the vital role played by miRNAs in regulating various aspects of circadian clock function. In our study, the miRNAs were analyzed in the samples of rice shoots harvested at the times of 2:00, 6:00, 10:00, 14:00, 18:00, and 22:00 through small RNA sequencing. When compared to the mid-night time point (2:00), we obtained differentially expressed mature miRNAs at the times of 6:00, 10:00, 14:00, 18:00, and 22:00. Four carbon and nitrogen metabolism-related miRNAs (osa-miR1440b, osa-miR2876-5p, osa-miR1877, and
osa-miR5799) were found to be regulated by natural light/dark cycle. The expression level analysis showed that the four carbon and nitrogen metabolism-related miRNAs negatively regulated their target genes at most of the time points. These results may provide a good strategy to study how natural light/dark cycle regulates carbon and nitrogen metabolism to ensure plant growth and development.

\section{AUTHOR CONTRIBUTIONS}

HC and FX designed the experiments, HL and ZL performed the experiments, HC and LS analyzed the data, GD contributed reagents, HC wrote the manuscript. All authors read and approved the manuscript.

\section{FUNDING}

This work was supported in part by grants from the National Key Research and Development Program of China (2016YFD0200108), the Fundamental Research Funds for the Central Universities (2662013PY041).

\section{SUPPLEMENTARY MATERIAL}

The Supplementary Material for this article can be found online at: http://journal.frontiersin.org/article/10.3389/fpls.2016. 01318 
Supplementary Figure S1 | The diagram of rice germination, planting, and harvesting.

Supplementary Figure S2 | The reads mapped to individual chromosome at the time of 2:00, 6:00, 10:00, 14:00, 18:00, and 22:00.

Supplementary Figure S3 | Heatmap of the mapped genes at the time of 2:00, 6:00, 10:00, 14:00, 18:00, and 22:00.

Supplementary Figure S4 | Functional categories of the mapped genes at the time of 2:00, 6:00, 10:00, 14:00, 18:00, and 22:00.

Supplementary Figure S5 | The alternative splicing events at the time of 2:00, 6:00, 10:00, 14:00, 18:00, and 22:00.

Supplementary Figure S6 | qRT-PCR analysis of nine randomly selected differentially expressed genes. Values are mean $\pm S D$ from three biological replicates.

Supplementary Figure S7 | The size distribution of unique sRNA sequences.
Supplementary Figure S8 | Heatmap of the mature miRNAs at the time of 2:00, 6:00, 10:00, 14:00, 18:00, and 22:00.

Supplementary Table S1 | Primer sequences used in qRT-PCR.

Supplementary Table S2 | Reads of mRNA sequencing in rice shoots at different time points.

Supplementary Table S3 | Mapped events of mRNA sequencing in rice shoots at different time points.

Supplementary Table S4 | Reads of small RNA sequencing in rice shoots at different time points.

Supplementary Table S5 | Number of mature miRNA in rice shoots at different time points.

Supplementary Table S6 | Target genes of osa-miR1440b, osa-miR2876-5p, osa-miR1877, and osa-miR5799 predicted by psRNATarget.

\section{REFERENCES}

Bao, A., Liang, Z., Zhao, Z., and Cai, H. (2015a). Overexpressing of OsAMT1-3, a high affinity ammonium transporter gene, modifies rice growth and carbonnitrogen metabolic status. Int. J. Mol. Sci. 16, 9037-9063. doi: 10.3390/ijms 16059037

Bao, A., Zhao, Z., Ding, G., Shi, L., Xu, F., and Cai, H. (2014). Accumulated expression level of cytosolic glutamine synthetase 1 gene (OsGS1;1 or OsGS1;2) alter plant development and the carbon-nitrogen metabolic status in rice. PLoS ONE 9:e95581. doi: 10.1371/journal.pone.0095581

Bao, A., Zhao, Z., Ding, G., Shi, L., Xu, F., and Cai, H. (2015b). The stable level of glutamine synthetase 2 plays an important role in rice growth and in carbon-nitrogen metabolic balance. Int. J. Mol. Sci. 16, 12713-12736. doi: 10.3390/ijms160612713

Bartok, O., Kyriacou, C. P., Levine, J., Sehgal, A., and Kadener, S. (2013). Adaptation of molecular circadian clockwork to environmental changes: a role for alternative splicing and miRNAs. Proc. Biol. Sci. 280, 20130011. doi: 10.1098/rspb.2013.0011

Bieniawska, Z., Espinoza, C., Schlereth, A., Sulpice, R., Hincha, D. K., and Hannah, M. A. (2008). Disruption of the Arabidopsis circadian clock is responsible for extensive variation in the cold-responsive transcriptome. Plant Physiol. 147, 263-279. doi: 10.1104/pp.108.118059

Bradford, M. M. (1976). A rapid and sensitive method for the quantitation of microgram quantities of protein utilizing the principle of protein binding. Anal. Biochem. 72, 248-254. doi: 10.1016/0003-2697(76)90527-3

Cáceres, J. F., and Kornblihtt, A. R. (2002). Alternative splicing: multiple control mechanisms and involvement inhuman disease. Trends Genet. 18, 186-193. doi: 10.1016/S0168-9525(01)02626-9

Chow, B. Y., and Kay, S. A. (2013). Global approaches for telling time: omics and the Arabidopsis circadian clock. Semin. Cell Dev. Biol. 24, 383-392. doi: 10.1016/j.semcdb.2013.02.005

Coruzzi, G. M., and Zhou, L. (2001). Carbon and nitrogen sensing and signaling in plants: emerging 'matrix effects.' Curr. Opin. Plant Biol. 4, 247-253. doi: 10.1016/S1369-5266(00)00168-0

Covington, M. F., Maloof, J. N., Straume, M., Kay, S. A., and Harmer, S. L. (2008). Global transcriptome analysis reveals circadian regulation of key pathways in plant growth and development. Genome Biol. 9:R130. doi: 10.1186/gb-2008-98-r130

Crawford, N. M., and Forde, B. G. (2002). "Molecular and developmental biology of inorganic nitrogen nutrition," in The Arabidopsis Book, Vol. 46, eds E. Meyerowitz and C. Somerville (Rockville, MD: American Society of Plant Biologists). doi: 10.1199/tab.0011

Dodd, A. N., Salathia, N., Hall, A., Kévei, E., Tóth, R., Nagy, F., et al. (2005). Plant circadian clocks increase photosynthesis, growth, survival, and competitive advantage. Science 309, 630-633. doi: 10.1126/science.1115581

Edwards, C. E., Ewers, B. E., Williams, D. G., Xie, Q., Lou, P., Xu, X., et al. (2011). The genetic architecture of ecophysiological and circadian traits in Brassica rapa. Genetics 189, 375-390. doi: 10.1534/genetics.110.125112

Espinoza, C., Degenkolbe, T., Caldana, C., Zuther, E., Leisse, A., Willmitzer, L., et al. (2010). Interaction with diurnal and circadian regulation results in dynamic metabolic and transcriptional changes during cold acclimation in Arabidopsis. PLoS ONE 5:e14101. doi: 10.1371/journal.pone.0014101

Filichkin, S. A., Priest, H. D., Givan, S. A., Shen, R., Bryant, D. W., Fox, S. E., et al. (2010). Genome wide mapping of alternative splicing in Arabidopsis thaliana. Genome Res. 20, 45-58. doi: 10.1101/gr.093302.109

Frink, C. R., Waggoner, P. E., and Ausubel, J. H. (1999). Nitrogen fertilizer: retrospect and prospect. Proc. Natl. Acad. Sci. U.S.A. 96, 1175-1180. doi: 10.1073/pnas.96.4.1175

Gibon, Y., Bläsing, O. E., Palacios-Rojas, N., Pankovic, D., Hendriks, J. H. M., Fisahn, J., et al. (2004). Adjustment of diurnal starch turnover to short days: depletion of sugar during the night leads to a temporary inhibition of carbohydrate utilization, accumulation of sugars and post-translational activation of ADP-glucose pyrophosphorylase in the following light period. Plant J. 39, 847-862. doi: 10.1111/j.1365-313X.2004.02173.x

Gould, P. D., Locke, J. C. W., Larue, C., Southern, M. M., Davis, S. J., Hanano, S., et al. (2006). The molecular basis of temperature compensation in the Arabidopsis circadian clock. Plant Cell 18, 1177-1187. doi: 10.1105/tpc. 105.039990

Graf, A., Schlereth, A., Stitt, M., and Smith, A. M. (2010). Circadian control of carbohydrate availability for growth in Arabidopsis plants at night. Proc. Natl. Acad. Sci. U.S.A. 107, 9458-9463. doi: 10.1073/pnas.0914299107

Graf, A., and Smith, A. M. (2011). Starch and the clock: the dark side of plant productivity. Trends Plant Sci. 16, 169-175. doi: 10.1016/j.tplants.2010.12.003

Green, R. M., Tingay, S., Wang, Z. Y., and Tobin, E. M. (2002). Circadian rhythms confer a higher level of fitness to Arabidopsis plants. Plant Physiol. 129, 576-584. doi: $10.1104 / p p .004374$

Gutiérrez, R. A., Stokes, T. L., Thum, K., Xu, X., Obertello, M., Katari, M. S., et al. (2008). Systems approach identifies an organic nitrogen-responsive gene network that is regulated by the master clock control gene CCA1. Proc. Natl. Acad. Sci. U.S.A. 105, 4939-4944. doi: 10.1073/pnas.0800211105

Harmer, S. L. (2009). The circadian system in higher plants. Annu. Rev. Plant Biol. 60, 357-377. doi: 10.1146/annurev.arplant.043008.092054

Harmer, S. L., Hogenesch, J. B., Straume, M., Chang, H., Han, B., Zhu, T., et al. (2000). Orchestrated transcription of key pathways in Arabidopsis by the circadian clock. Science 290, 2110-2113. doi: 10.1126/science.290.5499.2110

Harrison, J., Pou de Crescenzo, M. A., Sene, O., and Hirel, B. (2003). Does lowering glutamine synthetase activity in nodules modifying nitrogen metabolism and growth of Lotus japonicus? Plant Physiol. 133, 253-262. doi: 10.1104/pp.102.016766

Hausler, R. E., Blackwell, R. D., Lea, P. J., and Leegood, R. C. (1994). Control of photosynthesis in barley leaves with reduced activities of glutamine synthetase and glutamate synthase: plant characteristics and changes in nitrate, ammonium and amino acids. Planta 194, 406-417. doi: 10.1007/ BF00197542

Hecht, U., Oelmüller, R., Schmidt, S., and Mohr, H. (1988). Action of light, nitrate and ammonium on the levels of NADH- and ferredoxin-dependent glutamate 
synthases in the cotyledons of mustard seedlings. Planta 175, 130-138. doi: 10.1007/BF00402890

James, A. B., Syed, N. H., Bordag, S., Marshall, J., Nimmo, G. A., Jenkins, G. I., et al. (2012). Alternative splicing mediates responses of the Arabidopsis circadian clock to temperature changes. Plant Cell 24, 961-981. doi: 10.1105/ tpc. 111.093948

Kanehisa, M., Goto, S., Kawashima, S., Okuno, Y., and Hattori, M. (2004). The KEGG resource for deciphering the genome. Nucleic Acids Res. 32, D277-D280. doi: 10.1093/nar/gkh063

Kates, J. R., and Jones, R. F. (1964). Variation in alanine dehydrogenase and glutamate dehydrogenase during the synchronous development of Chlamydomonas. Biochem. Biophys. Acta 86, 438-447. doi: 10.1016/03044165(64)90083-2

Kerwin, R. E., Jimenez-Gomez, J. M., Fulop, D., Harmer, S. L., Maloof, J. N., and Kliebenstein, D. J. (2011). Network quantitative trait loci mapping of circadian clock outputs identifies metabolic pathway-to-clock linkages in Arabidopsis. Plant Cell 23, 471-485. doi: 10.1105/tpc.110.082065

Krapp, A., Ferrario-Méry, S., and Touraine, B. (2002). "Nitrogen and signaling," in Advances in Photosynthesis, Vol. 12, eds C. Foyer and G. Noctor (Dordrecht: Springer Netherlands), 205-225. doi: 10.1007/0-306-48138-3_13

Krapp, A., and Truong, H. N. (2005). "Regulation of C/N interaction in model plant species," in Enhancing the Efficiency of Nitrogen Utilization in Plants, eds S. Goyal, R. Tischner, A. Basra (New York, NY: Haworth Press), 127-173.

Lai, A. G., Doherty, C. J., Mueller-Roeber, B., Kay, S. A., Schippers, J. H. M., and Dijkwel, P. P. (2012). CIRCADIAN CLOCK-ASSOCIATED 1 regulates ROS homeostasis and oxidative stress responses. Proc. Natl. Acad. Sci. U.S.A. 109, 17129-17134. doi: 10.1073/pnas.1209148109

Lakin-Thomas, P. L. (2006). Transcriptional feedback oscillators: maybe, maybe not. J. Biol. Rhyth. 21, 83-92. doi: 10.1177/0748730405286102

Lam, H. M., Coschigano, K. T., Oliveira, I. C., Melo-Oliveira, R., and Coruzzi, G. M. (1996). The molecular-genetics of nitrogen assimilation into amino acids in higher plants. Ann. Rev. Plant Physiol. Plant Mol. Biol. 47, 569-593. doi: 10.1146/annurev.arplant.47.1.569

Lu, Y., Gehan, J. P., and Sharkey, T. D. (2005). Daylength and circadian effects on starch degradation and maltose metabolism. Plant Physiol. 138, 2280-2291. doi: 10.1104/pp.105.061903

Lynch, M., and Conery, J. S. (2000). The evolutionary fate and consequences of duplicate genes. Science 290, 1151-1155. doi: 10.1126/science.290.5494.1151

Maness, N. (2010). Extraction and analysis of soluble carbohydrates. Methods Mol. Biol. 639, 341-370. doi: 10.1007/978-1-60761-702-0_22

Martin, T., Oswald, O., and Graham, I. A. (2002). Arabidopsis seedling growth, storage lipid mobilization and photosynthetic gene expression are regulated by carbon: nitrogen availability. Plant Physiol. 128, 472-481. doi: 10.1104/pp.010475

Melo, P. M., Lima, L. M., Santos, I. M., Carvalho, H. G., and Cullimore, J. V. (2003). Expression of the plastid-located glutamine synthetase of Medicago truncatula: accumulation of the precursor in root nodules reveals an in vivo control at the level of protein import into plastids. Plant Physiol. 132, 390-399. doi: 10.1104/pp.102.016675

Mergenhagen, D., and Schweiger, H.-G. (1975). The effect of different inhibitors of transcription and translationon the expression and control of circadian rhythm in individual cells of Acetabularia. Exp. Cell Res. 94, 321-326. doi: 10.1016/0014-4827(75)90499-1

Michael, T. P., Mockler, T. C., Breton, G., McEntee, C., Byer, A., Trout, J. D., et al. (2008). Network discovery pipeline elucidates conserved time-of-day-specific cis-regulatory modules. PLoS Genet. 4:e14. doi: 10.1371/journal.pgen.0040014

Migge, A., Carrayol, E., Kuntz, C., Hirel, B., Fock, H., and Becker, T. (1997). The expression of the tobacco genes encoding plastidic glutamine synthetase or ferredoxin-dependent glutamate synthase does not depend on the rate of nitrate reduction, and is unaffected by suppression of photorespiration. J. Exp. Bot. 48, 1175-1181. doi: 10.1093/jxb/48.6.1175

Morris, D. L. (1948). Quantitative determination of carbohydrates with Dreywood's anthrone reagent. Science 107, 254-255. doi: 10.1126/science. 107.2775.254

Nakagawa, H., Yonemura, Y., Yamamoto, H., Ogura, N., and Sato, R. (1985). Spinach nitrate reductase. Purification, molecular weight, and subunit composition. Plant Physiol. 77, 124-128. doi: 10.1104/pp.77.1.124
Nunes, C., O’Hara, L. E., Primavesi, L. F., Delatte, T. L., Schluepmann, H., Somsen, G. W., et al. (2013). The trehalose 6-phosphate/SnRK1 signaling pathway primes growth recovery following relief of sink limitation. Plant Physiol. 162, 1720-1732. doi: 10.1104/pp.113.220657

Nunes-Nesi, A., Fernie, A. R., and Stitt, M. (2010). Metabolic and signaling aspects underpinning the regulation of plant carbon nitrogen interactions. Mol. Plant 3, 973-996. doi: 10.1093/mp/ssq049

Paul, M. J., Jhurreea, D., Zhang, Y., Primavesi, L. F., Delatte, T., Schluepmann, H., et al. (2010). Upregulation of biosynthetic processes associated with growth by trehalose 6-phosphate. Plant Signal. Behav. 5, 386-392. doi: 10.4161/psb. 5.4.10792

Porra, R. J., Thompson, W. A., and Kriedemann, P. E. (1989). Determination of accurate extinction coefficients and simultaneous equations for assaying chlorophylls $\mathrm{a}$ and $\mathrm{b}$ extracted with four different solvents: verification of the concentration of chlorophyll standards by atomic absorption spectroscopy. Biochem. Biophys. Acta 975, 384-394. doi: 10.1016/s0005-2728(89)80347-0

Powell, S., Szklarczyk, D., Trachana, K., Roth, A., Kuhn, M., Muller, J., et al. (2011). eggNOG v3.0: orthologous groups covering 1133 organisms at 41 different taxonomic ranges. Nucleic Acids Res. 40, D284-D289. doi: 10.1093/nar/gkr1060

Sato, Y., Takehisa, H., Kamatsuki, K., Minami, H., Namiki, N., Ikawa, H., et al. (2013). RiceXPro version 3.0: expanding the informatics resource for rice transcriptome. Nucleic Acids Res. 41, D1206-D1213. doi: 10.1093/nar/gks1125

Seaton, D. D., Ebenhöh, O., Millar, A. J., and Pokhilko, A. (2014). Regulatory principles and experimental approaches to the circadian control of starch turnover. J. R. Soc. Interface 11, 20130979. doi: 10.1098/rsif.2013.0979

Smith, A. M., and Stitt, M. (2007). Coordination of carbon supply and plant growth. Plant Cell Environ. 30, 1126-1149. doi: 10.1111/j.1365-3040. 2007.01708.x

Staiger, D., and Green, R. (2011). RNA-based regulation in the plant circadian clock. Trends Plant Sci. 16, 517-523. doi: 10.1016/j.tplants.2011.06.002

Tabuchi, M., Abiko, T., and Yamaya, T. (2007). Assimilation of ammonium ions and reutilization of nitrogen in rice (Oryza sativa L.). J. Exp. Bot. 58, 2319-2327. doi: 10.1093/jxb/erm016

Tatusov, R. L., Fedorova, N. D., Jackson, J. D., Jacobs, A. R., Kiryutin, B., Koonin, E. V., et al. (2003). The COG database: an updated version includes eukaryotes. BMC Bioinform. 4:41. doi: 10.1186/1471-2105-4-41

Turek, F. W., Joshu, C., Kohsaka, A., Lin, E., Ivanova, G., McDearmon, E., et al. (2005). Obesity and metabolic syndrome in circadian clock mutant mice. Science 308, 1043-1045. doi: 10.1126/science.1108750

Tuskan, G. A., Difazio, S., Jansson, S., Bohlmann, J., Grigoriev, I., Hellsten, U., et al. (2006). The genome of black cottonwood, Populustrichocarpa (Torr. \& Gray). Science 313, 1596-1604. doi: 10.1126/science.1128691

Yerushalmi, S., Yakir, E., and Green, R. M. (2011). Circadian clock and adaptation in Arabidopsis. Mol. Ecol. 20, 1155-1165. doi: 10.1111/j.1365294X.2010.04962.x

Zeeman, S. C., and Rees, T. A. P. (1999). Changes in carbohydrate metabolism and assimilate partitioning in starch excess mutants of Arabidopsis. Plant Cell Environ. 22, 1445-1453. doi: 10.1046/j.1365-3040.1999.00503.x

Zhang, Y. H., Primavesi, L. F., Jhurreea, D., Andralojc, P. J., Mitchell, R. A. C., Powers, S. J., et al. (2009). Inhibition of SNF1-related protein kinase1 activity and regulation of metabolic pathways by trehalose-6-phosphate. Plant Physiol. 149, 1860-1871. doi: 10.1104/pp.108.133934

Zhang, Z. L. (1990). Guide to Plant Physiology Experiments. Beijing: Higher Education Press.

Zheng, Z. (2009). Carbon and nitrogen nutrient balance signaling in plants. Plant Signal. Behav. 4, 584-591. doi: 10.4161/psb.4.7.8540

Conflict of Interest Statement: The authors declare that the research was conducted in the absence of any commercial or financial relationships that could be construed as a potential conflict of interest.

Copyright (C) 2016 Li, Liang, Ding, Shi, Xu and Cai. This is an open-access article distributed under the terms of the Creative Commons Attribution License (CC BY). The use, distribution or reproduction in other forums is permitted, provided the original author(s) or licensor are credited and that the original publication in this journal is cited, in accordance with accepted academic practice. No use, distribution or reproduction is permitted which does not comply with these terms. 